\title{
NORMAS Y CUMPLIMIENTO EN ÁREAS DE MANEJO DE RECURSOS BENTÓNICOS* ESTUDIO DE CASO EN LA REGIÓN DEL BÍO-BÍO
}

\author{
Mario Palma y \\ Carlos Chávez
}

\begin{abstract}
Este trabajo describe formas de organización y normas de funcionamiento en áreas de manejo y explotación de recursos bentónicos de la Región del Bío-Bío. Adicionalmente, en base a una encuesta especial aplicada a pescadores integrantes de las organizaciones, se reportan resultados de una evaluación respecto de cumplimiento de normas de extracción y cooperación. Se concluye que aun cuando las áreas consideradas presentan aspectos de organización y funcionamiento similares, existen diferencias en relación a sistemas de vigilancia empleados y reglas de distribución de beneficios económicos. Los resultados de la encuesta indican que mientras un $18 \%$ de los pescadores se declara infractor de la norma que restringe la extrac-
\end{abstract}

Mario Palma Guillén. Magíster en Economía de Recursos Naturales y del Medio Ambiente, Universidad de Concepción, Analista sector agroforestal, Unidad de Apoyo Técnico (UNAT), Secretaría Despacho Presidencial, Honduras. Es también Investigador Asociado al Instituto Economía y Recursos Naturales, Perú. E-mail: mpalma@sdp.gob.hn.

Carlos Chávez Rebolledo. Doctor of Philosophy (Ph. D.), Economía Ambiental y Recursos Naturales, University of Massachusetts, Amherst, Estados Unidos. Profesor Asociado, Departamento de Economía, Universidad de Concepción, Casilla 1987, Concepción, Chile. E-mail: cchavez@udec.cl.

* Agradecemos a los directorios y socios integrantes de las organizaciones de pescadores de las áreas de manejo de recursos bentónicos de Candelaria Cantera, Dichato, Lirquén y Puerto Yana por su valiosa colaboración durante el trabajo de campo. Asimismo, agradecemos los comentarios y útiles sugerencias de dos árbitros anónimos que han contribuido a mejorar este trabajo.

Estudios Públicos, 103 (invierno 2006). 
ción de recursos, un 43\% de ellos reconoce transgredir normas de cooperación. El perfil socioeconómico de los pescadores artesanales infractores, su percepción respecto de la legitimidad de la regulación y dirigentes, y el sentido de pertenencia a sus organizaciones son también analizados.

\section{Introducción}

$\mathrm{L}$ (AMERB) constituyen una novedosa forma de administración pesquera basada en la asignación de derechos de uso territorial para el manejo comunitario. Este sistema de administración considera aspectos referidos tanto a la participación de la población asignataria de los derechos en los procesos de decisión que afectan el manejo y uso de recursos bentónicos, así como también en la definición de los derechos al interior del área de manejo.

El uso de las AMERB ha tendido a difundirse masivamente a través de toda la costa del país desde el año 1997. Considerando datos del Servicio Nacional de Pesca (SERNAPESCA), durante el año 2003 el número total de AMERB decretadas a nivel nacional ascendía a 488, con un total de aproximadamente 93 mil hectáreas asignadas, involucrando a un número aproximado de 21 mil pescadores artesanales ${ }^{2}$. En igual período, en la Región del Bío-Bío el número de áreas decretadas alcanzaba a 61, con una superficie total de 22 mil hectáreas y cerca de 3 mil pescadores participando como socios de las organizaciones involucradas ${ }^{3}$. En la Región del Bío-Bío existían también a esa fecha cerca de 40 áreas solicitadas.

A pesar de la creciente importancia de este novedoso sistema de administración pesquera, en nuestro conocimiento no existen trabajos que hayan abordado de manera sistemática el estudio respecto de normas de funcionamiento de las asociaciones de pescadores, y la evaluación del grado de cumplimiento interno de las mismas. Este artículo es una contribución al

${ }^{1}$ Las AMERB constituyen una medida de administración pesquera concebida en la Ley General de Pesca y Acuicultura de 1991. Aspectos específicos de diseño y funcionamiento de esta medida de administración fueron definidos en 1995 a través del Decreto Supremo 355.

${ }^{2}$ La información fue obtenida a través de contacto personal con encargado de la sección pesca artesanal, SERNAPESCA, VIII Región.

${ }^{3}$ El número de áreas decretadas puede ser mayor al número de áreas que efectivamente se encuentran operando, por ejemplo, algunas organizaciones de pescadores han renunciado al área una vez que ésta fue decretada. 
estudio empírico del desarrollo de las áreas de manejo en nuestro país y en la Región del Bío-Bío en particular. Es pertinente precisar, sin embargo, que existe una cantidad importante de trabajos publicados referidos a áreas de manejo y explotación de recursos bentónicos en Chile. La mayoría de éstos considera aspectos biológicos y técnicos asociados a su funcionamiento (véase por ejemplo Castilla y Fernández [1998], y Jerez [2001], entre otros). Un análisis inicial de la medida de administración, incluyendo sus orígenes, así como una descripción general de sus principales aspectos, es provista por González (1996). Un estudio de casos que examina factores de éxito en las caletas de El Quisco y Quintay se encuentra en Cereceda y Czischke (2001). Adicionalmente, Agüero (2001) realiza una evaluación social y económica de esta medida de administración. Finalmente, un análisis teórico sobre cumplimiento de normas de extracción y monitoreo de pares en el contexto de derechos de uso territorial es provisto por Villena y Chávez (2005) ${ }^{4}$.

Dos son los principales objetivos de este trabajo. Primero, realizar una descripción de la organización y funcionamiento en áreas de manejo y explotación de recursos bentónicos. Segundo, presentar los resultados de una evaluación en relación a resultados de cumplimiento interno de normas de funcionamiento de las organizaciones, así como respecto del perfil de los pescadores de acuerdo a su condición de cumplimiento (transgresión) de las normas estudiadas ${ }^{5}$.

Nuestro análisis está basado en un estudio de casos de una muestra de áreas de manejo actualmente decretadas y en funcionamiento en la costa de la Región del Bío-Bío. Con el propósito de lograr los objetivos planteados, se desarrolló un proceso de selección de AMERB a estudiar. Dicho proceso se llevó a cabo en dos etapas. En la etapa inicial se procedió a analizar información sobre la antigüedad de las organizaciones asignatarias de la Región del Bío-Bío y las especies principales que explotan. En la etapa siguiente del proceso de selección, se procedió a desarrollar un acercamiento hacia las organizaciones seleccionadas a fin de poder determinar el grado de disponibilidad de los pescadores a cooperar para llevar a cabo el estudio.

\footnotetext{
${ }^{4}$ Agradecemos a un árbitro anónimo de Estudios Públicos por sugerir esta precisión e indicarnos una de las referencias.

${ }^{5}$ Una precisión es necesaria en relación a este punto. Aun cuando pescadores individuales pueden transgredir tanto normas de las organizaciones a las cuales ellos están adscritos como también normas de otras organizaciones, como lo es, por ejemplo, la restricción (prohibición) de extracción de determinado(s) recurso(s); nuestro trabajo considera sólo el análisis de cumplimiento interno. Ello no significa que las infracciones o transgresiones de agentes externos no sean importantes. El análisis de cumplimiento considerando dicho tipo de transgresores constituye una posible extensión de esta investigación.
} 
Como resultado del proceso de selección se decidió trabajar con las organizaciones de Dichato (Sindicato de Trabajadores Independientes del Mar y Acuicultores de la Pesca Artesanal Caleta Dichato), Lirquén (Sindicato de Trabajadores Independientes, Buzos Mariscadores de Lirquén), Candelaria Cantera (Sindicato de Trabajadores Independientes de la Pesca Artesanal y Buzos Mariscadores de Caleta Cantera) y Puerto Yana (Sindicato de Trabajadores Independientes de la Pesca Artesanal y Actividades Afines de Caleta Yana). La información base del estudio, cuyos resultados reportamos, tiene dos fuentes principales: entrevistas estructuradas realizadas a los dirigentes de las organizaciones seleccionadas, y una encuesta especial individual aplicada a los socios de las organizaciones consideradas. Mientras la información proporcionada por la primera fuente es utilizada para el cumplimiento del primer objetivo, la encuesta individual fue diseñada con el propósito de recoger información que permitiera cumplir el segundo objetivo antes indicado. Adicionalmente, la información anterior fue complementada con la revisión de reglamentos internos y otros documentos referidos al funcionamiento de las organizaciones.

El trabajo se organiza en cinco secciones. La sección 2 contiene la descripción general de aspectos legales básicos considerados en la Ley y reglamentos que sustentan las AMERB. Adicionalmente, se incluye aquí una breve descripción de la situación actual respecto del uso de áreas de manejo como sistema de administración en la Región del Bío-Bío.

La sección 3 presenta resultados del estudio de casos en relación a normas de organización y funcionamiento de las AMERB seleccionadas. En esta sección se describe el proceso de selección utilizado para determinar las organizaciones a estudiar. A continuación se presentan los resultados obtenidos respecto a la descripción del funcionamiento de las áreas de manejo seleccionadas en aspectos referidos a representatividad, derechos y obligaciones, faltas y sanciones, sistema de vigilancia, y comercialización de cosechas y distribución de beneficios.

En la sección 4 reportamos los resultados obtenidos en base al análisis de la encuesta especial aplicada a los socios integrantes de las organizaciones estudiadas. Luego de una breve descripción de la encuesta, se presenta un análisis de los resultados respecto del comportamiento individual en relación al cumplimiento de las normas de funcionamiento de las organizaciones. Dos normas claves son consideradas en el análisis: prohibición de extracción del recurso loco (concholepas concholepas), y norma de cooperación y participación en actividades de vigilancia de las áreas. El rol de factores determinantes del comportamiento individual es considerado en un análisis descriptivo. Se incluyen aquí un perfil 
socioeconómico de los pescadores infractores de normas, así como un análisis de su percepción respecto de sanciones, legitimidad de los dirigentes, y sentido de pertenencia a sus organizaciones. Las conclusiones que se desprenden de nuestro trabajo se presentan en la sección 5.

\section{Descripción general del sistema de regulación de las AMERB}

En esta sección se presenta una breve descripción de aspectos conceptuales referidos a problemas y alternativa de solución para el manejo de recursos de propiedad común. Luego se presenta una descripción de la base legal que sustenta las AMERB como medida de administración pesquera. Finalmente, se presenta una breve descripción del estado de aplicación de las áreas de manejo de la Región del Bío-Bío.

\subsection{Autoadministración como alternativa para manejo de recursos de propiedad común}

La explotación de recursos bentónicos de parte de pescadores artesanales constituye un ejemplo de utilización de recursos de propiedad común. Conceptualmente existen dos características claves que definen este tipo de bienes o recursos. Primero, la presencia de rivalidad en el uso de éste entre actuales y potenciales agentes. Esta característica implica que la utilización del recurso de parte de un agente reduce la oferta disponible del recurso para otros agentes. Segundo, los recursos de propiedad común se caracterizan también por la ausencia de exclusión. La referida característica implica que, en el caso de estos recursos, el impedir la utilización de parte de un agente individual o de un grupo de agentes es imposible o difícil de implementar. La existencia de recursos de propiedad común genera incentivos individuales que no necesariamente corresponden con objetivos de grupo, de manera que resultados socialmente no deseables, tales como exceso de utilización o explotación de recursos naturales, y ausencia de cooperación entre los agentes, son los resultados y conductas esperadas en diversos contextos ${ }^{6}$.

${ }^{6}$ La predicción de resultado socialmente inferior en el caso de ausencia de la característica de exclusión ha sido también planteada de manera alternativa de la siguiente forma: cuando sea que un agente no pueda ser excluido de lo que otros proveen, cada individuo está motivado a no contribuir al esfuerzo conjunto, pero sí a beneficiarse a costa del esfuerzo de otros. Si todos los participantes eligen beneficiarse sin esfuerzo propio, el beneficio colectivo no se producirá. El punto es relevante al estudiar el comportamiento individual referido al respeto a las normas en el manejo de 
Una solución al problema de manejo de recursos de propiedad común, la cual constituye el foco de atención de esta investigación, es aquella en la que los involucrados, en este caso los propios pescadores artesanales, pueden hacer un contrato limitado de negociación, y de esta manera acordar y desarrollar una estrategia cooperativa que ellos mismos harán funcionar. En este esquema de manejo de recursos de propiedad común, son los agentes involucrados quienes poseen los derechos de uso y explotación del recurso, definen las formas de organización y las normas de funcionamiento, y son responsables de la vigilancia y actividades de fiscalización para inducir el cumplimiento de éstas ${ }^{7}$.

En relación a la autoadministración y autorregulación para el manejo de recursos de propiedad común, existen estudios recientes que tienden a identificar características que definen su desempeño. Específicamente, Walker et al. (2000) determinaron que los individuos que se comunican directamente antes de tomar decisiones sobre el uso de los recursos son capaces de incrementar su beneficio en comparación con las organizaciones en que dicha comunicación no existe. Los referidos autores encontraron también que las organizaciones en las cuales se logra la comunicación directa y se desarrollan procesos de votación para determinar las sanciones a quienes no cumplan las normas establecidas, logran mejores resultados, con niveles bajos de detección de transgresiones (violaciones) y consecuentemente imposición de sanciones poco frecuente ${ }^{8}$.

\subsection{Creación y asignación de derechos de uso territorial en Chile}

Las áreas de manejo y explotación de recursos bentónicos (AMERB) constituyen una forma de administración pesquera basada en la participación organizada de los pescadores en los procesos de decisión que

recursos de propiedad común, como es el caso de las AMERB, ya que aquellos que no respetan las normas actúan como "polizones” usufructuando del esfuerzo del resto del grupo.

7 Desde un punto de vista normativo, la literatura ha discutido también soluciones alternativas a los problemas que plantea la presencia de rivalidad y no exclusión para el manejo adecuado de recursos de propiedad común; entre ellas cabe destacar la existencia de una autoridad central, y la creación y asignación de derechos de propiedad privada [véase por ejemplo Berkes et al. (1988), Ostrom (1990), y Seabright (1993), entre otros].

${ }^{8}$ Estudios experimentales sobre comportamiento individual han encontrado también que los procedimientos de elección de reglas juegan un papel importante en los resultados de grupo. En el artículo de Walker et al. (2000) se presenta una extensa descripción de literatura relacionada a los procedimientos de elección y sus roles en organizaciones comunitarias. 
afectan el manejo y uso de recursos. Las AMERB son una medida de administración mediante la cual se asignan derechos exclusivos de uso y explotación de recursos bentónicos de sectores geográficos ubicados en la franja costera de las cinco millas reservadas a la pesca artesanal o en aguas terrestres e interiores. Los derechos son asignados a organizaciones de pescadores artesanales legalmente constituidas ${ }^{9}$.

Desde un punto de vista operativo, la asignación de derechos de uso territorial a organizaciones de pescadores requiere el cumplimiento de un proceso que incluye diversas acciones específicas. El proceso se inicia con la presentación de una solicitud de asignación de área de manejo. La solicitud debe presentarse por escrito al Servicio Nacional de Pesca, firmada por representantes legales de la respectiva organización de pescadores (sindicatos, cooperativas, asociaciones gremiales) y acompañada de todos los antecedentes especificados en el Artículo 9, incisos a, b, c, d, e, del Reglamento sobre Áreas de Manejo y Explotación de Recursos Bentónicos (D.S. No 572), Ministerio de Economía, Fomento y Reconstrucción (2000). Una vez que la organización ha presentado la solicitud acompañada por, entre otros antecedentes, la proposición y realización de un estudio de situación base (ESBA), y la formulación de un plan de manejo y explotación del área (PMEA), los que son sancionados por la Subsecretaría de Pesca, el Servicio Nacional de Pesca entrega el sector a la organización mediante un convenio de uso por un período de cuatro años, renovables ${ }^{10}$. Los sectores

${ }^{9}$ Esta forma de administración pesquera se encuentra establecida en la Ley General de Pesca y Acuicultura No 18.892 (LGPA), letra d del Artículo 48, título IV. La cual fue aprobada mediante Decreto Supremo № 430 del 28 de septiembre de 1991, del Ministerio de Economía, Fomento y Reconstrucción. Exceptuando el límite de franja costera de cinco millas reservadas a la pesca artesanal, no existen restricciones de espacio físico para las AMERB. Considérese por ejemplo que hasta el año 2003, en la Región del Bío-Bío, la superficie de áreas con convenio de uso fluctuaba entre un mínimo de 6,7 hectáreas para una organización del sector Roca Fraile en la comuna de Arauco y un máximo de 4.096,4 hectáreas en el caso de una AMERB del sector oeste de Isla Mocha, en la comuna de Lebu. Es interesante destacar que el número de socios en ambas organizaciones no difería significativamente, alcanzando a 78 y 86 integrantes, respectivamente.

${ }^{10} \mathrm{El}$ estudio de situación base (ESBA) es un documento que contempla la incorporación de un plan de muestreo en el área, basado en los estándares metodológicos y criterios técnicos mínimos, adecuados para la caracterización del Área de Manejo solicitada. La finalidad es la recopilación de antecedentes técnicos y componentes bióticos presentes en el área (distribución, composición, cuantía, entre otros) así como los componentes abióticos (referidos a características físicas del área). El Plan de Manejo debe ser realizado por la organización de pescadores con la asesoría técnica de una institución ligada a las ciencias del mar, de acuerdo al Artículo 21, título VI del RAM. 
geográficos involucrados son previamente establecidos como “disponibles para AMERB” mediante decreto supremo del Ministerio de Economía, previa consulta a la Subsecretaría de Marina y con informes técnicos de la Subsecretaría de Pesca y del Consejo Zonal de Pesca respectivo. Una vez publicado dicho decreto en el Diario Oficial, el Servicio Nacional de Pesca solicita la correspondiente destinación al Ministerio de Defensa Nacional.

El plan de manejo y explotación (PMEA) contempla la presentación de informes anuales de seguimiento de desempeño del área. La presentación de tales informes es responsabilidad de la organización de pescadores asesorada por una entidad ejecutora pertinente (Artículo 19 bis, Reglamento de Áreas de Manejo). El informe de seguimiento debe incluir, entre otros datos, la información sobre cosechas y acciones de manejo realizadas en el período anterior, análisis del desempeño general del área, acciones de manejo del próximo período y los resultados esperados ${ }^{11}$. Finalizado el cuarto año de vigencia del convenio de uso, la organización debe pagar durante el mes de marzo de cada año una patente única de área de manejo de beneficio fiscal, la cual se ha determinado en un valor equivalente a una unidad tributaria mensual (UTM) por cada hectárea o fracción de hectárea entregada como AMERB de acuerdo al convenio de uso.

\section{3 Áreas de manejo en la Región del Bío-Bío}

En el primer trimestre del año 2003 en la Región del Bío-Bío había un total de 97 sectores que habían sido solicitados como AMERB. De este total, solamente 61 sectores habían sido decretados como áreas de manejo en distintos momentos del período 1997-2003, las cuales se encontraban en diferentes estados de operación, incluyendo áreas que habían sido sólo recientemente decretadas hasta aquellas más antiguas que estaban realizando cosechas anuales, incluso con un tercer informe de seguimiento respecto a su desempeño.

Las AMERB decretadas están distribuidas a lo largo de toda la costa de la Región del Bío-Bío, cubriendo un área aproximada de 21.930 has. Las organizaciones de pescadores a las que se les han asignado las áreas de manejo están constituidas en su mayoría como sindicatos, existiendo también cooperativas, asociaciones gremiales, asociaciones indígenas y organizaciones comunitarias; las que aún no han sido decretadas se

${ }^{11}$ Reglamento sobre Áreas de Manejo y Explotación de Recursos Bentónicos, publicado en el Diario Oficial de1 26/08/95; última modificación, D.S. № 253, del 05/ 12/02, publicado Diario Oficial del 24/02/03. 
encuentran en un proceso de oposición con otras áreas decretadas, o en trámite de decreto, o con renuncia de la organización, entre otras determinadas por la ley y el reglamento de las AMERB.

La Tabla No 1 muestra el número de las Áreas de Manejo decretadas, pescadores beneficiados (socios de las organizaciones), superficie, y densidad por provincia y comuna en la VIII Región. Según se observa allí, en la Región del Bío-Bío existen cerca de 3.000 pescadores artesanales asociados a las 61 organizaciones beneficiarias de las áreas de manejo decretadas, y que se encuentran en distintos estados ${ }^{12}$. La provincia de Concepción reporta el mayor número de organizaciones, ascendiendo éste a 31, seguida por la provincia de Arauco con 27 organizaciones. Esta última provincia registra también el mayor número de pescadores asociados y la mayor superficie, con más de 1.300 socios y una superficie total de cerca de 17 mil hectáreas (véase Tabla № 1). Ello se refleja también en la baja densidad calculada para el caso de áreas de manejo en Arauco. En dicha provin-

TABLA N ${ }^{\circ}$ 1: NÚMERO DE SOCIOS, SUPERFICIE, Y DENSIDAD EN AMERB DECRETADAS EN LA REGIÓN DEL BÍO-BÍO ${ }^{a}$

\begin{tabular}{|c|c|c|c|c|c|c|c|}
\hline \multirow{2}{*}{ Provincia/Com. } & \multirow{2}{*}{$\begin{array}{c}\mathrm{N}^{\circ} \\
\text { AMERB }\end{array}$} & \multirow{2}{*}{$\begin{array}{c}\mathrm{N}^{\mathrm{o}} \\
\text { Socios }\end{array}$} & \multirow{2}{*}{$\begin{array}{c}\text { Superf. } \\
\text { (Has) }\end{array}$} & \multirow{2}{*}{$\begin{array}{c}\text { Densidad } \\
\text { (Socio/Ha) }\end{array}$} & \multicolumn{3}{|c|}{ Porcentaje } \\
\hline & & & & & AMERB & Socios & Superf. \\
\hline Arauco & 27 & 1.326 & 16.874 & 0,08 & 44,3 & 48,6 & 76,8 \\
\hline Arauco & 16 & 672 & 1.123 & 0,60 & & & \\
\hline Lebu & 3 & 354 & 5.465 & 0,06 & & & \\
\hline Cañete & 2 & 27 & 3.627 & 0,01 & & & \\
\hline Tirúa & 6 & 273 & 6.659 & 0,04 & & & \\
\hline Concepción & 31 & 1.296 & 2.929 & 0,44 & 50,8 & 47,5 & 13,4 \\
\hline Talcahuano & 6 & 233 & 343 & 0,68 & & & \\
\hline Lota & 3 & 86 & 118 & 0,73 & & & \\
\hline Penco & 9 & 283 & 442 & 0,64 & & & \\
\hline San Pedro de la Paz & 1 & 19 & 139 & 0,14 & & & \\
\hline Tomé & 5 & 263 & 456 & 0,58 & & & \\
\hline Coronel & 7 & 412 & 1.431 & 0,29 & & & \\
\hline$\tilde{N} u b l e$ & 3 & 101 & 2.122 & 0,05 & 4,9 & 3,7 & 9,8 \\
\hline Cobquecura & 1 & 39 & 425 & 0,09 & & & \\
\hline Coelemu & 2 & 62 & 1.697 & 0,04 & & & \\
\hline Total & 61 & 2.697 & 21.930 & 0,12 & 100,0 & 100,0 & 100,0 \\
\hline
\end{tabular}

a Incluye sólo áreas decretadas antes de febrero de 2003.

Fuente: Elaboración propia en base a datos provistos por SERNAPESCA.

12 El estado de las áreas se refiere al nivel en que se encuentra la gestión de ésta, lo cual incluye desde el tercer seguimiento en las Áreas de Manejo más antiguas y que ya han tenido una o varias extracciones, hasta aquellas que, estando decretadas, se encuentran aún esperando resolución de estudio de situación base (ESBA). 
cia el número de socios por hectárea promedio es de 0.08 , en contraste con aquel calculado para la provincia de Concepción, que alcanza a 0.44 socios por hectárea (véase Tabla $\mathrm{N}^{\circ} 1$, columna 5).

\section{Estudio de casos: Normas de funcionamiento en AMERB de la Región del Bío-Bío}

En esta sección se presentan resultados del estudio de casos respecto de normas de funcionamiento y organización en las AMERB seleccionadas. La sección se inicia con una descripción del proceso de selección utilizado para determinar las organizaciones a estudiar. Seguidamente, se presentan los resultados obtenidos en base a las entrevistas estructuradas realizadas a los dirigentes de las organizaciones en relación a representatividad, derechos y obligaciones, faltas y sanciones, comercialización de cosecha y distribución de beneficios.

\subsection{Proceso de selección de las áreas de manejo a estudiar}

El proceso de selección de las organizaciones estudiadas se desarrolló en dos etapas. En la fase inicial se procedió al análisis de información tendiente a seleccionar las organizaciones de pescadores que serían sujeto de estudio. Este proceso incluyó el análisis de una serie de variables que nos proporcionaron información detallada de la antigüedad y de las especies objetivo principales. En esta etapa se tomaron en cuenta los siguientes factores:

- Primero, que la organización tuviera convenio de uso, estado de seguimiento (se prefirió a las organizaciones que estaban en el proceso de seguimiento más alto; $3^{\mathrm{er}}$ seguimiento, ingreso $3^{\mathrm{er}}$ seguimiento, $2^{\text {do }}$ seguimiento, ingreso $2^{\text {do }}$ seguimiento, en ese orden), estos dos factores nos permitieron determinar la antigüedad ${ }^{13}$;

- Segundo, se consideró la especie principal explotada por la AMERB. La especie principal es aquel recurso hidrobiológico cuya explotación controlada es la finalidad fundamental del proyecto de manejo y explotación. Considerando este aspecto, se procedió a seleccionar las AMERB

13 El Plan de Manejo y Explotación (PMEA) contempla la presentación de informes anuales de seguimiento (Artículo 19 bis, RAM), el cual contiene, entre otros datos, la información sobre cosechas y acciones de manejo realizadas en el período anterior, análisis del desempeño general del área, acciones de manejo del próximo período y los resultados esperados. 
que tuvieran como especie principal o entre sus especies principales la explotación de loco (concholepas concholepas) ${ }^{14}$.

En la segunda fase del proceso de selección de áreas de manejo se procedió a desarrollar un acercamiento a las organizaciones seleccionadas para determinar el grado de disponibilidad de los pescadores a cooperar para llevar a cabo el estudio. Producto del proceso de selección se decidió trabajar con las organizaciones de Dichato, Lirquén, Candelaria Cantera y Puerto Yana ${ }^{15}$.

La Tabla $N^{\circ} 2$ presenta un listado de las organizaciones elegidas como resultado del proceso de selección, en dicha tabla se incluye, entre otros datos, el nombre de la organización, la ubicación geográfica, el nivel de seguimiento en que se encuentra, el número de socios y la superficie.

\subsection{Funcionamiento de las áreas de manejo seleccionadas}

Esta sección describe las normas de funcionamiento y administración de las organizaciones seleccionadas. Éstas presentan algunas normas y formas de funcionamiento o administración que son comunes a todas ellas; sin embargo, también presentan algunas normas de funcionamiento y administración que son propias de cada una de ellas. La información necesaria para conocer el funcionamiento de las organizaciones seleccionadas se obtuvo a partir de entrevistas a miembros claves de las organizaciones, así como de documentos tales como: reglamentos internos y actas de constitución de las organizaciones. Entre otros, se describen aspectos referidos a la representatividad en las organizaciones, derechos, obligaciones, faltas y sanciones, sistema de vigilancia, comercialización y la distribución de beneficios. En el caso de las organizaciones que tienen socias mujeres entre

\footnotetext{
14 Otras especies cuyo manejo es reportado por las organizaciones son cholga, macha o navajuela, huepo, erizo, choro y pelillo. El foco de atención de este trabajo en la especie loco se explica por dos razones principales. Primero, es una especie común en la Región del Bío-Bío, de hecho en más del 80\% de las organizaciones de la Región que al año 2003 tenían convenio de uso y seguimiento, la referida especie es declarada como una entre las tres principales. Segundo, la especie loco posee un alto valor comercial, y constituye una pesquería de alto desarrollo, el que se acentuó principalmente durante la década de los ochenta, originando una sobreexplotación del recurso, lo cual fue seguido por la introducción de medidas de administración tendientes a asegurar su conservación, especialmente durante la primera mitad de la década pasada. La especie loco pertenece a la familia Thaididae, su máximo desove se produce en verano, vive adherido a la parte baja de las rocas desde la zona interior de las bajas mareas hasta los 15 metros de profundidad.

15 Aun cuando fue seleccionada en la etapa inicial, lamentablemente no fue posible obtener la cooperación de parte de la organización de San Vicente.
} 
TABLA N ${ }^{\circ}$ 2: $\quad$ PRINCIPALES CARACTERÍSTICAS DE AMERB SELECCIONADAS PARA ESTUDIO DE CASOS

\begin{tabular}{|c|c|c|c|c|c|c|c|}
\hline Orden $^{a}$ & $\begin{array}{l}\text { Caleta } \\
\text { (Sector) }\end{array}$ & $\begin{array}{l}\text { Organización } \\
\text { Beneficiaria }\end{array}$ & Comuna & Estado & $\begin{array}{c}\text { Fecha } \\
\text { Convenio } \\
\text { de uso }\end{array}$ & $\begin{array}{l}\text { Superf. } \\
\text { (Has) }\end{array}$ & $\begin{array}{c}\mathrm{N}^{\mathrm{o}} \\
\text { Socios }\end{array}$ \\
\hline \multirow[t]{2}{*}{1} & Dichato & $\begin{array}{l}\text { Sindicato de } \\
\text { trabajadores } \\
\text { independientes } \\
\text { del mar y } \\
\text { acuicultores de } \\
\text { la pesca artesanal } \\
\text { Caleta Dichato. }\end{array}$ & Tomé & $\begin{array}{l}3^{\mathrm{er}} \\
\text { seguim. }\end{array}$ & $\begin{array}{l}\text { Marzo } \\
2000\end{array}$ & 107,5 & 87 \\
\hline & $\begin{array}{l}\text { Punta } \\
\text { Lirquén }\end{array}$ & $\begin{array}{l}\text { Sindicato de } \\
\text { trabajadores } \\
\text { independientes, } \\
\text { buzos mariscadores } \\
\text { de Lirquén. }\end{array}$ & Penco & $\begin{array}{l}3^{\mathrm{er}} \\
\text { seguim. }\end{array}$ & $\begin{array}{l}\text { Marzo } \\
2000\end{array}$ & 45,9 & 23 \\
\hline \multirow[t]{2}{*}{2} & $\begin{array}{l}\text { Candelaria } \\
\text { Cantera }\end{array}$ & $\begin{array}{l}\text { Sindicato de } \\
\text { trabajadores } \\
\text { independientes, } \\
\text { pescadores } \\
\text { artesanales y } \\
\text { buzos mariscadores } \\
\text { de Caleta Cantera. }\end{array}$ & Talcahuano & $\begin{array}{l}2^{\text {do }} \\
\text { seguim. }\end{array}$ & $\begin{array}{l}\text { Mayo } \\
2000\end{array}$ & 73,8 & 61 \\
\hline & Pta. Yana & $\begin{array}{l}\text { Sindicato de } \\
\text { trabajadores } \\
\text { independientes de } \\
\text { la pesca artesanal } \\
\text { y actividades afines } \\
\text { de Caleta Yana }\end{array}$ & $\begin{array}{l}\text { Arauco } \\
\text { S }\end{array}$ & $\begin{array}{l}2^{\text {do }} \\
\text { seguim. }\end{array}$ & Agosto & 112,5 & 36 \\
\hline Total & & & & & & 525,5 & 294 \\
\hline
\end{tabular}

a Se refiere al orden de prioridad o interés para la investigación, producto del cumplimiento de los requisitos establecidos por el investigador (antigüedad, especie principal, entre otros).

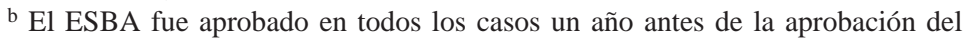
convenio de uso (1999).

Fuente: Elaboración propia, en base a datos de SERNAPESCA y SUBPESCA.

sus afiliados se describe brevemente el papel desempeñado por ellas en la organización ${ }^{16}$.

Representatividad: La asamblea constituye la máxima autoridad de las organizaciones estudiadas, integran ésta todos los miembros de la

${ }^{16}$ El Anexo contiene una matriz comparativa de las normas de administración de cada organización. 
organización, quienes poseen derecho a voz y voto ${ }^{17}$. De acuerdo a los estatutos pueden pertenecer a cada organización los trabajadores que se desempeñan en forma independiente como pescadores artesanales, buzos mariscadores o ayudantes de buzo, extractores de algas y recolectores de orilla; que estén debidamente inscritos en el Registro Nacional de Pesca y que residan en la caleta (comunidad) donde se encuentra establecida la organización. Los pescadores interesados en ingresar a la organización deben presentar una solicitud de ingreso, la cual, para ser efectiva, deberá ser aprobada por la mayoría de la asamblea ${ }^{18}$.

En relación al proceso de elección de directorio de la organización, las cuatro organizaciones estudiadas utilizan el sistema de votación secreta, en donde cada uno de los asociados elige dos preferencias de los postulantes a dirigentes. En cada proceso eleccionario, se constituye un órgano calificador de las elecciones, conformado por tres socios elegidos por mayoría simple de los presentes en asamblea extraordinaria convocada para tal fin, quienes son los encargados de recibir las postulaciones, implementar la elección (desarrollo de requisitos legales, entre los cuales se puede mencionar el dar a conocer el proceso a la Inspección del Trabajo respectiva), así como supervisar el acto eleccionario y certificar los resultados, sin perjuicio de aquellos actos en que la ley requiera la presencia de un ministro de fe. Las directivas de las organizaciones estudiadas son elegidas para desarrollar sus funciones por un período de dos años. El directorio (o directiva) está constituido por tres miembros: presidente, secretario y tesorero, quienes son los responsables de representar a la organización judicial y extrajudicialmente y velar por el logro de los objetivos de la organización, así como también administrar el patrimonio de la organización ${ }^{19}$. Es interesante precisar que en ninguna de las organizaciones estudiadas se contempla remuneración por el desempeño de cargos directivos, sino sólo el pago de gastos de representación de la organización. Adicionalmente, el detalle de responsabilidades de cada cargo se encuentra especificado de manera genérica en

17 Se pierde el derecho a voz y voto cuando se transgreden disposiciones del Reglamento Interno de la organización. El ente encargado de aplicar las sanciones es la Junta directiva. Existen entidades a nivel interno de la organización que son consideradas al momento de determinar los castigos, entre éstas podemos mencionar, comité de disciplina y encargados de vigilancia.

${ }^{18}$ En algunas organizaciones se estipula el pago de una cuota de incorporación, alcanzando ésta en determinados casos un valor de 1 UTM.

${ }^{19} \mathrm{El}$ patrimonio de la organización incluye activos, tales como: espacio físico y construcciones que constituyen la sede de la organización de pescadores artesanales, mobiliario y equipos de vigilancia. Naturalmente, estos activos varían en cantidad y valor entre las organizaciones. 
las escrituras de constitución de cada organización, las cuales no presentan variaciones entre las organizaciones estudiadas.

Entre las normas de funcionamiento y administración propias de cada organización se pueden mencionar el número de socios necesarios para sesionar (quórum), el cual varía entre un mínimo de $25 \%$ en Candelaria Cantera y un 51\% en Dichato. Adicionalmente, existen diferencias en la asignación de los cargos de los directores elegidos. En el caso de Puerto Yana los cargos son asignados de acuerdo a la cantidad de votos (primera mayoría, presidente; segunda mayoría, secretario; tercera mayoría, tesorero); en tanto que en la organización de Lirquén el presidente elegido (primera mayoría) designa los cargos de secretario y tesorero entre las dos siguientes mayorías. Finalmente, en Candelaria Cantera existe una forma alternativa de designación de cargos. Ésta consiste en que los tres postulantes que logran las primeras mayorías acuerdan entre ellos la forma de designación de los cargos (véase Anexo, “Modo elección de directiva”).

Derechos y obligaciones: Los derechos de los cuales goza cada uno de los miembros de las organizaciones son básicamente los mismos en las cuatro organizaciones estudiadas. Se pueden mencionar, entre otros, el participar de los beneficios producto de las cosechas y ser representados por la organización. Hay algunos derechos que no son comunes en todas las organizaciones. En este sentido es interesante hacer notar el derecho de herencia en caso de muerte del socio. Este derecho existe en las organizaciones de Dichato y Candelaria Cantera, y consiste en que, en caso de fallecimiento del titular, sus derechos son traspasados a sus familiares directos.

Las obligaciones son similares en las organizaciones, consistiendo fundamentalmente en respetar las normas generales definidas (respeto mutuo de los miembros, asistir a reuniones, etc.). Entre las obligaciones especiales producto de la naturaleza de las áreas de manejo, se encuentra el participar de las labores de vigilancia y respetar las cuotas de extracción ${ }^{20}$. También se incluye como una obligación el pago mensual de una cuota a la organización. El monto difiere de una organización a otra y fluctúa entre $\$ 500$ y \$1.000. Los referidos fondos son utilizados para financiar gastos de operación de la organización, uso que se encuentra especificado en las escrituras de constitución de cada una de ellas.

${ }^{20}$ En la sección 4 reportamos resultados de cumplimiento de ambas normas en base a una encuesta individual aplicada a socios de las organizaciones estudiadas. 
Faltas y sanciones: Se consideran como faltas el no cumplimiento de las obligaciones descritas anteriormente. Las sanciones están estipuladas de acuerdo a la falta que se comete. Por ejemplo, el extraer recursos de manera ilegal se sanciona la primera vez con la exclusión de participación de los beneficios de la cosecha o de una fracción de ella. En caso de ser encontrado reincidiendo, el socio es expulsado definitivamente de la organización; dicha sanción es común en las cuatro organizaciones. Sin embargo, en algunas organizaciones se contempla el reingreso de los socios expulsados luego de un tiempo de castigo (véase Anexo, “Reintegro por expulsión”). El faltar a las labores de vigilancia o no facilitar el equipo para desarrollar labores de la organización se sanciona en algunas organizaciones con la pérdida de un porcentaje de los beneficios de la cosecha. Éste es el caso en las organizaciones de Dichato, Lirquén y Candelaria Cantera. Específicamente, en Puerto Yana esta falta se sanciona con el pago de una multa en efectivo, que asciende a \$ 10.000 por turno no realizado.

Sistema de vigilancia: En la generalidad de las organizaciones estudiadas el sistema de vigilancia consiste en un grupo de socios, cuyo tamaño varía de una organización a otra (tres o cuatro), que cumplen un sistema de turnos. Los referidos grupos realizan rondas de guardia en el perímetro del área respectiva. Estos son los encargados de revisar todo el recurso extraído.

En todas las organizaciones existe un rol de vigilancia basado en un calendario de turnos. Hay un "encargado de guardia”, quien es el responsable de que se cumpla con el rol de vigilancia, entregar y recibir los materiales y equipos de vigilancia (bote, motor, binoculares, entre otros). El “encargado de guardia” también debe informar tanto a los dirigentes de la organización como a la autoridad pertinente (Capitanía de Puerto, Carabineros de Chile, y/o SERNAPESCA) en caso de ser detectada alguna anormalidad en el área. De igual manera, el "encargado de guardia” debe informar a los dirigentes los casos de los socios que no están cumpliendo con su labor de vigilancia o que hayan sido detectados extrayendo recursos de manera ilegal. En la organización de Puerto Yana esta función es desarrollada por las mujeres miembros de la organización ${ }^{21}$. En el caso de

${ }^{21}$ En efecto, en la organización de Puerto Yana las mujeres desempeñan un papel especial. Son las encargadas de desarrollar la labor de "encargado de guardia”, es decir, verificar que se cumpla con el rol de vigilancia; adicionalmente, son las encargadas de realizar la limpieza de la sede de la organización y del recurso extraído en períodos de cosecha. Las mujeres desarrollan la labor de encargados de guardia en un promedio de tres turnos por mes. 
Candelaria Cantera se cuenta con un guardia nocturno, quien es un socio de la organización, al cual se le paga un sueldo fijo mensual; lo anterior no lo exime de cumplir con su turno en el rol de vigilancia. Los integrantes de algunas organizaciones estudiadas desarrollan también, aunque de manera no sistemática, labores de vigilancia desde el borde costero. Ello funciona como un complemento a la actividad de los grupos encargados de la vigilancia. Estas actividades incluyen el monitoreo esporádico del área de parte de pescadores socios de la organización respectiva, lo cual es desarrollado durante períodos de descanso de los pescadores desde ubicaciones cercanas al área y que poseen adecuada visibilidad. Naturalmente, las áreas difieren en cuanto a la factibilidad de este tipo de inspección, la que a su vez depende de, entre otras, las características geográficas específicas ${ }^{22}$.

Existen también diferencias en relación a los sistemas de vigilancia entre las organizaciones consideradas. La organización de Dichato reportó la realización de vigilancia a través de guardias desde el borde costero. El propósito de ésta sería evitar confabulación entre guardias de turno que patrullan el área y extractores. En la referida área se ha dado autorización para desarrollar actividad de recolección de algas a personas que no son miembros de la organización. Adicionalmente, se detectaron también diferencias en la cantidad de turnos mensuales por organización, siendo éstos crecientes en el número de socios integrantes. Finalmente, en algunas organizaciones los costos de la vigilancia son financiados por la organización (Dichato, Lirquén, Puerto Yana) en tanto que en Candelaria Cantera los costos son cubiertos por la cuadrilla encargada de realizar el turno.

Comercialización de cosechas y distribución de beneficios: La comercialización es realizada por una comisión de ventas existente en cada organización. La comisión de ventas está encargada de negociar los detalles de la venta del producto a las empresas compradoras (precios, cantidades, etc.). En la mayoría de las organizaciones la venta se realiza en forma grupal, existiendo solamente una en la cual la venta (entrega del producto, una vez efectuada la negociación por parte de la comisión de ventas) se lleva a cabo de manera individual. Los resultados de las entrevistas estructuradas sugieren que la comercialización constituye un punto sensible y es percibido como de central importancia por la dirigencia de las organizaciones. Especí-

22 En este sentido existen áreas más "transparentes” y otras más "opacas" dependiendo de la topografía del espacio físico y borde costero en que éstas se ubican, así como también en cuanto a la localización de las viviendas de los socios que integran la respectiva organización. 
ficamente, los pescadores reportan un número muy reducido de compradores (en la mayoría de los casos sólo un comprador), constituyendo una negociación del tipo monopolio bilateral. Los resultados de negociaciones de precios en dicho contexto están determinados por el poder de negociación de las partes involucradas. Al respecto, se detecta que una debilidad de las organizaciones es el de restricción de capital de trabajo para financiar las actividades de cosecha de locos (por ejemplo, gastos de combustible para operar motores de botes). En al menos una de las organizaciones consideradas en este estudio, el comprador actúa facilitando el capital de trabajo, proporcionando financiamiento requerido como un pago anticipado de la compra de la cosecha respectiva. Ello es percibido por dirigentes como una ventaja para el comprador al momento de negociar precios de la transacción.

En relación a la distribución de los beneficios, se presentan algunas diferencias de una organización a otra. En algunas organizaciones el monto neto de ventas (ingresos totales por venta menos los costos de administración y operación) es dividido entre el total de socios que no están sancionados. En este caso es pertinente aclarar que cada socio que facilita su equipo para las labores de extracción obtiene una bonificación extra (incluida en los gastos de operación) ${ }^{23}$. En la organización de Lirquén, donde la venta (entrega) se hace en forma individual, se reparte la cuota total permitida entre el total de socios (no se incluyen los socios sancionados), el socio que facilita su equipo recibe doble cuota. En este caso, un $20 \%$ de la cuota total permitida corresponde a la organización y está destinada a cubrir los gastos de funcionamiento de la misma, incluyendo, entre otros, gastos de representación, mantenimiento y funcionamiento de la sede de la organización (gastos de energía eléctrica, agua, etc.). El manejo de estos fondos está regulado por el reglamento interno. Para realizar auditorías sobre el uso de dichos fondos existe en cada organización una comisión revisora de cuentas que actúa como un ente fiscalizador, que utiliza, entre otros instrumentos, el presupuesto anual (en el cual se especifican las partidas y sus montos) y facturas y comprobantes de gastos. La comisión de ventas es la responsable de la venta de la cuota correspondiente a la organización y de reportar estos ingresos al tesorero de la organización.

En el caso de la organización de Candelaria Cantera, se destina un $10 \%$ de los ingresos totales producto de la venta a los fondos de la propia organización, del 90\% restante de los ingresos se descuentan los gastos de

\footnotetext{
${ }^{23}$ Equipo comprende el bote con todos sus implementos.
} 
extracción (combustible, aceite de motor), luego el monto neto, una vez realizados los descuentos anteriormente especificados, es distribuido de la siguiente forma: un $50 \%$ está destinado a los buzos, un $15 \%$ es repartido entre los ayudantes de buzos y el 35\% restante es distribuido entre los dueños de embarcaciones.

Finalmente, la organización de Puerto Yana utiliza un sistema de montos fijos para distribuir los beneficios, el primer monto (\$5.000.000) se reparte entre los buzos de la organización. Del monto que le corresponde cada buzo destina el 50\% para sí mismo, 25\% para el dueño de la embarcación (por uso de equipo), el 25\% restante se reparte en aportes iguales entre el remero y el ayudante del buzo. El segundo monto fijo de $\$ 2.000 .000$ es asignado a la organización. Del eventual ingreso restante, el 20\% es repartido entre las mujeres de la organización, la diferencia hasta completar el total de la venta se reparte en partes iguales entre los hombres de la organización sin importar su especialidad. En el caso particular de esta organización, el combustible necesario para las labores de extracción es proporcionado por la empresa compradora (véase detalles en Anexo, "Comercialización” y “Distribución de utilidades”).

\section{Resultados de encuesta sobre cumplimiento de normas en AMERB}

En esta sección reportamos los resultados obtenidos respecto de cumplimiento de normas en las AMERB estudiadas. El análisis del comportamiento referido a cumplimiento de normas está basado en información obtenida a través del diseño de una encuesta especial aplicada de manera confidencial e individual a miembros de las organizaciones consideradas. La encuesta se aplicó durante los meses de septiembre, octubre y noviembre del año 2003.

La Tabla $\mathrm{N}^{\circ} 3$ presenta un resumen de la aplicación de la encuesta. Ésta contiene el número de socios que fueron encuestados en cada organización, los socios que no colaboraron, es decir, aquellos que fueron abordados por el investigador pero que se negaron a responder la encuesta, los socios que presentan una situación especial (“congelados”), y finalmente aquellos integrantes de las organizaciones que por distintos motivos no fueron entrevistados ${ }^{24}$. La encuesta fue aplicada a un total de 155 de los 207 socios inscritos en las organizaciones consideradas.

${ }^{24}$ Entre estos motivos se puede mencionar el caso de algunos socios que nunca fueron localizados, otros socios que por lo avanzado de su edad y/o por motivos de enfermedad los familiares no permitieron realizar la encuesta. 
TABLA N ${ }^{\circ}$ :

DISTRIBUCIÓN DE SOCIOS Y ENCUESTAS APLICADAS SEGÚN AMERB

\begin{tabular}{lccccc}
\hline Organización & $\begin{array}{c}\text { Total } \\
\text { Socios }\end{array}$ & Encuestados & $\begin{array}{c}\text { No } \\
\text { colaboraron }\end{array}$ & $\begin{array}{c}\text { No } \\
\text { Congelados }^{\text {a }}\end{array}$ & $\begin{array}{l}\text { encuestados } \\
\text { Dichato }\end{array}$ \\
Lirquén & 87 & 51 & 6 & 20 & 10 \\
Candelaria Cantera & 61 & 22 & 57 & & 1 \\
Puerto Yana & 36 & 35 & & 20 & 1 \\
\hline Total & 207 & 155 & 11 & 21 \\
\hline
\end{tabular}

a Se refiere a los miembros que están fuera de la Caleta, que no participan de las obligaciones de vigilancia, tampoco participan de la extracción la temporada que congelan.

Fuente: Elaboración propia en base a desarrollo de encuesta.

La encuesta aplicada está dividida en once secciones, las cuales recogen los datos sobre la información individual (para mantener la confidencialidad no se preguntó el nombre u otros datos que pudieran identificar al pescador), las características de los equipos y los costos de extracción, comercialización, una sección que captura la percepción que el pescador tiene sobre la probabilidad de detección y sanción, percepción y condición de cumplimiento, nivel de compromiso del pescador con su organización y la percepción que el pescador tiene sobre los derechos de uso y explotación de los recursos bentónicos al interior del área de manejo ${ }^{25}$.

\section{Características socioeconómicas de los encuestados}

La Tabla $N^{\circ} 4$ presenta una caracterización socioeconómica de los pescadores encuestados. Se presentan allí, según AMERB de pertenencia de los pescadores, edad promedio, distribución según especialidad, distribución según niveles de educación, nivel de ingresos, tamaño del grupo familiar, porcentaje de pescadores que declaran obtener ingresos exclusivamente de la pesca, número de años promedio de experiencia en el sector pesquero y el porcentaje de los encuestados que declara ser propietario de bote.

${ }^{25}$ La encuesta aplicada está disponible y sólo debe ser requerida directamente a los autores. Con el propósito de evitar extender innecesariamente el artículo, hemos decidido no incorporar aquí el detalle de la encuesta. No obstante, y considerando la relevancia que poseen las preguntas utilizadas para definir la condición de cumplimiento de normas de los pescadores encuestados, se incluye una descripción específica de tales preguntas, así como el procedimiento elegido para definir la condición de cumplimiento individual de los encuestados (véase subsección Cumplimiento de Normas). Agradecemos a un árbitro anónimo de Estudios Públicos por motivar esta precisión. 
La edad promedio de los socios encuestados bordea los 41 años, siendo ésta levemente inferior en el caso de socios de Puerto Yana (36 años) y superior en el caso de socios de la organización de Lirquén (44 años). Con respecto al nivel de educación, solamente el $2 \%$ de los encuestados dice no tener escolaridad. En tanto que un 57\% declara tener enseñanza básica completa, el 16\% tiene como máximo enseñanza media completa y un 2\% tiene enseñanza técnica o universitaria incompleta (véase Tabla $\mathrm{N}^{0} 4$ ). La distribución de nivel de educación es similar entre organizaciones, excepto en Puerto Yana donde la mayoría de los encuestados posee sólo enseñanza básica. En relación a la especialidad, observamos que la mayoría de los encuestados es buzo o auxiliar de buzo (52\%), en tanto que el 16\% de éstos son patrones de embarcación, y un 25\% tiene como especialidad el ser tripulante pescador. El 7\% restante de los encuestados reporta como especialidad ser recolectores de algas.

En relación al nivel de ingreso promedio mensual, las respuestas de los encuestados sugieren que éstos son en general bajos. Específicamente, el 55\% de los pescadores de las AMERB consideradas en el estudio no supera los \$ 100.000 como ingreso promedio mensual, adicionalmente un $35 \%$ declara tener un ingreso mensual promedio entre \$ 100.000 y \$ 200.000 . Finalmente, sólo un $10 \%$ de los encuestados reporta poseer un ingreso promedio mensual superior a \$200.000 (véanse detalles según área de manejo en Tabla $\left.N^{\circ} 4\right)$. Respecto a la fuente de ingresos, el 74\% de los encuestados dice tener la pesca como única y exclusiva fuente de ingreso. Es interesante notar que la excepción en este caso la constituye Puerto Yana, donde sólo el 46\% de los pescadores encuestados declara que sus ingresos dependen exclusivamente de la pesca. Ello se explica porque en la referida AMERB también se desarrolla actividad agrícola de pequeña escala, la cual genera producción para autoconsumo y venta de excedentes, así como actividades de recolección de algas y faenas forestales de carácter esporádico.

En relación al número de integrantes del grupo familiar que dependen económicamente del pescador, los resultados de la encuesta sugieren que el promedio es de 4 personas. Éste es superior en Puerto Yana donde el grupo familiar bordea las 6 personas. Finalmente, el promedio de años de experiencia en labores de pesca es de 22 años, en tanto que un $42 \%$ de los pescadores encuestados dice tener bote propio $^{26}$.

\footnotetext{
${ }^{26}$ Éste puede ser propulsado por motor fuera de borda o por remos.
} 
TABLA N ${ }^{\circ}$ 4: CARACTERIZACIÓN SOCIOECONÓMICA ENCUESTA INTEGRANTES AMERB

\begin{tabular}{|c|c|c|c|c|c|}
\hline Variable & Dichato & Lirquén & $\begin{array}{c}\text { Candelaria } \\
\text { Cantera }\end{array}$ & $\begin{array}{c}\text { Puerto } \\
\text { Yana }\end{array}$ & Total \\
\hline Edad (años) & 41,3 & 44,2 & 41,2 & 36,1 & 40,5 \\
\hline
\end{tabular}

\section{Educación}

Sin educación

Básica incompleta

Básica completa

Media completa

Superior $^{\mathrm{a}}$

Total

\begin{tabular}{rrrrr}
1 & 1 & 0 & 2 & 4 \\
6 & 7 & 8 & 14 & 35 \\
31 & 9 & 30 & 18 & 88 \\
6 & 4 & 5 & 0 & 15 \\
2 & 0 & 1 & 0 & 3 \\
51 & 22 & 47 & 35 & 155 \\
\hline
\end{tabular}

\section{Especialidad}

\begin{tabular}{|c|c|c|c|c|c|}
\hline Patrón & 11 & 1 & 10 & 2 & 24 \\
\hline Buzo & 17 & 13 & 20 & 7 & 57 \\
\hline Auxiliar buzo & 8 & 5 & 5 & 6 & 24 \\
\hline Tripulante & 15 & 3 & 12 & 9 & 39 \\
\hline Recolector de algas & 0 & 0 & 0 & 11 & 11 \\
\hline Total & 51 & 22 & 47 & 35 & 155 \\
\hline \multicolumn{6}{|l|}{ Ingreso $^{b}$} \\
\hline Menos de $\$ 100.000$ & 28 & 13 & 14 & 31 & 86 \\
\hline De $\$ 100.000,01$ a $\$ 150.000$ & 11 & 6 & 15 & 2 & 34 \\
\hline De $\$ 150.000,01$ a $\$ 200.000$ & 9 & 1 & 8 & 1 & 19 \\
\hline Más de $\$ 200.000$ & 3 & 2 & 10 & 1 & 16 \\
\hline Total & 51 & 22 & 47 & 35 & 155 \\
\hline Tamaño grupo familiar & 3,8 & 3,5 & 3,7 & 5,7 & 4,2 \\
\hline Pesca como única fuente de ingreso & (\%)76 & 82 & 89 & 46 & 74 \\
\hline Experiencia & 23,2 & 26,9 & 25,2 & 13,9 & 22,2 \\
\hline Propietario de bote ${ }^{\mathrm{c}}(\%)$ & 41 & 45 & 55 & 23 & 42 \\
\hline
\end{tabular}

${ }^{a}$ Ésta puede ser técnica o universitaria.

${ }^{\mathrm{b}}$ Promedio mensual en pesos chilenos.

c Éste puede ser propulsado por motor fuera de borda o remos.

Fuente: Elaboración propia en base a información obtenida en la encuesta aplicada en el año 2003. 


\section{1 Cumplimiento de normas}

Se procedió a analizar la información obtenida a través de las encuestas individuales, agrupando a los pescadores de acuerdo a sus respuestas sobre cumplimiento de normas. Consideramos cuatro categorías principales: i) no infractores, ii) infractores de norma extracción, iii) infractores de norma de cooperación (no cooperadores), y, finalmente, iv) infractores de ambas normas ${ }^{27}$. La Tabla $N^{0} 5$ presenta el número de pesca-

TABLA N ${ }^{\circ}$ 5: $\quad$ RESULTADOS DE CUMPLIMIENTO NORMAS EN AMERB

\begin{tabular}{lrrrrr}
\hline Clasificación & Dichato & Lirquén & $\begin{array}{c}\text { Candelaria } \\
\text { Cantera }\end{array}$ & $\begin{array}{c}\text { Puerto } \\
\text { Yana }\end{array}$ & $\begin{array}{c}\text { Total } \\
\text { socios }\end{array}$ \\
\hline No infractores & 21 & 6 & 31 & 24 & 82 \\
Infractores norma extracción & & & 6 & 6 & 28 \\
Infractores norma cooperación $^{\mathrm{a}}$ & 14 & 6 & 2 & 8 & 66 \\
Infractores ambas normas & 27 & 16 & 15 & 3 & 21 \\
\hline Total & 11 & 6 & 1 & 41 & 197 \\
\hline
\end{tabular}

a En ambos casos incluye los 21 casos de infractores de ambas normas.

Fuente: Elaboración propia en base a resultado de encuesta.

${ }^{27}$ Nuestro análisis está basado en las respuestas de los pescadores encuestados, por lo tanto, la condición de cumplimiento para cada norma estudiada es aquella reportada por cada uno de los individuos considerados. Reconocemos que en nuestro análisis estamos asumiendo respuestas verdaderas de parte de los encuestados. Aun cuando el supuesto es inevitable, consideramos que las respuestas son confiables. Esta consideración se basa en que las encuestas fueron aplicadas individualmente por un único encuestador (uno de los coautores del trabajo), quien realizó continuas visitas a las caletas en que se ubican las organizaciones seleccionadas. En el caso de Puerto Yana, la caleta más alejada y con mayores dificultades de acceso de aquellas consideradas en el estudio, el encuestador residió con los pescadores durante todo el período en el que la encuesta fue desarrollada. La encuesta también consideró distintas preguntas para clasificar al pescador de acuerdo a su (in)cumplimiento de normas. Específicamente, gracias al diseño de la encuesta, se consideró como infractor de la norma de extracción a un pescador que reconociera haber sido alguna vez castigado por extraer recurso loco de manera ilegal desde que pertenece a la organización (la pregunta específica en este caso fue la siguiente: "En esta temporada o en alguna de las temporadas anteriores desde que pertenece usted a la organización o desde que funciona el Área de Manejo, ¿̇alguna vez fue usted castigado por extraer recurso loco de manera ilegal?”, las alternativas de respuesta son: “Más de una vez”, “una vez”, "nunca”). Adicionalmente, fue clasificado también como infractor de esta norma el pescador que, ante la pregunta “¿cuál de las siguientes frases describe mejor su actividad pesquera en esta temporada en el área de manejo, en lo que respecta a la extracción de locos?”, seleccionó, "rara vez cumplo con las regulaciones de extracción establecidas por la organización ya que las exigencias son 
dores en cada uno de los segmentos definidos. Desagregando el análisis y considerando la clasificación de los pescadores de acuerdo a su condición de cumplimiento, observamos que de los 155 miembros de las organizaciones encuestadas el 53\% reporta no ser infractor de ninguna de las dos normas consideradas. Adicionalmente, un $18 \%$ de los encuestados declara ser infractor de la norma de extracción, y un 43\% reconoce no cumplir con la norma de cooperación.

\subsection{Perfil socioeconómico de los pescadores infractores de normas}

Considerando la información disponible respecto de la condición de cumplimiento individual observada en los segmentos en los cuales los socios de las organizaciones han sido clasificados, es posible definir un perfil socioeconómico de los transgresores de las normas estudiadas. El perfil que se presenta a continuación está basado en el análisis de los resultados de la encuesta para el total de pescadores encuestados.

La Tabla $\mathrm{N}^{\circ} 6$ presenta la distribución de los pescadores por rango de edad de acuerdo a su condición de cumplimiento según normas consideradas. La mayor proporción de infractores de la norma de extracción se reporta en el rango de los 15 a los 38 años (5 de un total de 7 pescadores infractores de tal norma se encuentran en el referido rango). En el caso de los infractores de la norma de cooperación, la mayor incidencia se reporta en el rango de los 39 a los 61 años (25 de 45 pescadores infractores de la norma indicada se encuentran en el referido rango). El 57\% de los infractores de ambas normas se encuentra entre los 15 y los 38 años. Este último resultado sugiere que transgresores de ambas normas (extracción y cooperación) son predominantemente pescadores relativamente jóvenes.

muchas", y aquellos que reconocieron que "normalmente intento respetar las regulaciones de extracción, pero algunas veces enfrento situaciones en las que no puedo cumplir con lo que dicen las regulaciones”. De igual forma se consideró como transgresor de la norma de cooperación a todo pescador que aceptó haber sido sancionado por faltar a sus labores de vigilancia por lo menos una vez y/o que expuso, frente a una pregunta adicional de la encuesta, no haber prestado nunca su equipo o participado en actividades para el desarrollo de la organización. Las preguntas específicas en este caso fueron las siguientes: a) "En la última temporada, ¿cuántas veces fue usted sancionado por faltar a las labores de vigilancia?”, con respuestas posibles "una vez”, “más de una vez”, y "ninguna”; b) “¿Con qué frecuencia facilita usted su equipo para realizar labores de vigilancia”, con respuestas posibles “siempre”, “casi siempre”, “algunas veces” y "nunca”. Agradecemos a un árbitro anónimo de Estudios Públicos por plantear este punto y requerir estas precisiones. 
TABLA N ${ }^{\circ}$ 6: $\quad$ RESULTADOS DE CUMPLIMENTO DE NORMAS SEGÚN EDAD

\begin{tabular}{lcccrr}
\hline Rango edad & $\begin{array}{c}\text { No } \\
\text { infractores }\end{array}$ & $\begin{array}{c}\text { Infractores } \\
\text { norma } \\
\text { extracción }\end{array}$ & $\begin{array}{c}\text { Infractores } \\
\text { norma } \\
\text { cooperación }\end{array}$ & $\begin{array}{c}\text { Infractoras } \\
\text { ambas } \\
\text { normas }\end{array}$ & Total \\
\hline $15-27$ & 11 & 2 & 8 & 8 & 29 \\
$28-38$ & 22 & 3 & 10 & 4 & 39 \\
$39-50$ & 29 & 2 & 15 & 5 & 51 \\
$51-61$ & 17 & 0 & 10 & 0 & 51 \\
$62-73$ & 3 & 0 & 2 & 21 & 155 \\
\hline Total & 82 & 7 & 45 & & 5 \\
\hline
\end{tabular}

Fuente: Elaboración propia en base a resultado de encuesta.

Los resultados de incumplimiento o infracción a las normas según la especialidad de los encuestados sugieren que la mayor incidencia de infractores corresponde a los buzos o auxiliares de buzo. En efecto, en dichos casos, la incidencia de infracciones alcanza a 57\% de la norma de extracción y de la norma de cooperación y el 52\% de ambas normas. Esto sugiere que debido a la naturaleza de su trabajo es este grupo el que presenta una mayor propensión a infringir cualquiera de las dos normas bajo estudio y especialmente la norma de extracción. En el grupo de los tripulantes pescadores se reporta el $28 \%$ de los casos de infractores a la norma de extracción, igual porcentaje se reporta de no cooperadores, aumentando este porcentaje a un 33\% cuando se trata de infractores de ambas normas. Los patrones o dueños de embarcación presentan niveles de infracción menores, reportándose el 14\% del total de los infractores de la norma de cooperación y de infractores de ambas normas y un 13\% de los no cooperadores. Finalmente, la totalidad de los encuestados que declara como especialidad la de recolector de algas no reporta ser infractor de ninguna de las dos normas. Es de interés mencionar que este último caso se trata, en su mayoría, de mujeres que por la naturaleza de su trabajo no tienen experiencia en la extracción de recursos bentónicos y no poseen equipos para desarrollar dichas labores, lo cual puede explicar el nivel declarado de adhesión a la norma ${ }^{28}$. La Tabla $\mathrm{N}^{\mathrm{o}} 7$ presenta la distribución de comportamiento referido a cumplimiento de normas de los pescadores según su especialidad.

${ }^{28}$ La totalidad de las mujeres recolectoras de algas pertenece a la organización de Puerto Yana. 
TABLA N ${ }^{\circ}$ 7: $\quad$ RESULTADOS DE CUMPLIMENTO DE NORMAS SEGÚN ESPECIALIDAD

\begin{tabular}{lcccrc}
\hline & $\begin{array}{c}\text { No } \\
\text { Especialidad }\end{array}$ & $\begin{array}{c}\text { Infractores } \\
\text { norma } \\
\text { extracción }\end{array}$ & $\begin{array}{c}\text { Infractores } \\
\text { norma } \\
\text { cooperación }\end{array}$ & $\begin{array}{c}\text { Infractores } \\
\text { ambas } \\
\text { normas }\end{array}$ & Total \\
\hline Patrón & 14 & 1 & 6 & 3 & 24 \\
Buzo y auxiliar de buzo & 40 & 4 & 26 & 11 & 81 \\
Tripulante pescador & 17 & 2 & 13 & 7 & 39 \\
Recolector de algas & 11 & 0 & 0 & 0 & 11 \\
\hline Total & 82 & 7 & 45 & 21 & 155 \\
\hline
\end{tabular}

Fuente: Elaboración propia en base a resultado de encuesta.

En relación con el nivel de educación, los resultados obtenidos a través de la encuesta indican que la totalidad de los infractores de la norma de extracción reportan tener como máximo enseñanza básica completa, con este mismo nivel educativo se reporta el $89 \%$ de los no cooperadores y el $67 \%$ de los infractores de ambas normas. Este resultado nos permite caracterizar a los infractores de normas como poseedores de un relativamente bajo nivel de educación entre la totalidad de socios adscritos a las organizaciones estudiadas. La Tabla $\mathrm{N}^{\circ} 8$ presenta los resultados de cumplimiento de normas según nivel de educación de los pescadores.

TABLA N ${ }^{\circ}$ 8: $\quad$ RESULTADOS DE CUMPLIMIENTO DE NORMAS SEGÚN NIVEL DE EDUCACIÓN DE LOS PESCADORES

\begin{tabular}{lccccr}
\hline Especialidad & $\begin{array}{c}\text { No } \\
\text { infractores }\end{array}$ & $\begin{array}{c}\text { Infractores } \\
\text { norma } \\
\text { extracción }\end{array}$ & $\begin{array}{c}\text { Infractores } \\
\text { norma } \\
\text { cooperación }\end{array}$ & $\begin{array}{c}\text { Infractores } \\
\text { ambas } \\
\text { normas }\end{array}$ & Total \\
\hline $\begin{array}{l}\text { Ninguno } \\
\text { Enseñanza básica } \\
\text { incompleta }\end{array}$ & 3 & 0 & 0 & 1 & 4 \\
$\begin{array}{c}\text { Enseñanza básica } \\
\text { completa }\end{array}$ & 15 & 1 & 15 & 4 & 35 \\
$\begin{array}{c}\text { Enseñanza media } \\
\text { incompleta }\end{array}$ & 47 & 6 & 25 & 10 & 88 \\
$\begin{array}{c}\text { Enseñanza media } \\
\text { completa }\end{array}$ & 8 & 0 & 2 & 1 & 11 \\
$\begin{array}{c}\text { Enseñanza técn. o univ. } \\
\text { incompleta }\end{array}$ & 1 & 0 & 2 & 4 & 14 \\
\hline Total & 1 & 0 & 1 & 1 & 3 \\
\hline
\end{tabular}

Fuente: Elaboración propia en base a resultado de encuesta. 
En relación con los niveles de ingresos de los infractores, observamos que la mayor proporción de éstos, en cualquiera de las normas consideradas, reporta ingreso mensual promedio menor a los \$100.000. Específicamente, en este rango de ingresos se reportan el 57\% de los transgresores de la norma de extracción, el 60\% de los no cooperadores, y el 52\% de los infractores de ambas normas. Los pescadores que declaran obtener un ingreso promedio mensual en el rango de \$ 100.000 - \$ 200.000, son clasificados en su mayoría como infractores de las normas de cooperación (33\% de los infractores de esta norma) o infractores de ambas normas (el 38\% de los infractores de ambas normas). La Tabla No 9 presenta la distribución de cumplimiento de normas de acuerdo al nivel de ingreso de los pescadores encuestados.

CUMPLIMIENTO DE NORMAS SEGÚN NIVEL DE INGRESO DE LOS PESCADORES

\begin{tabular}{lccccc}
\hline & $\begin{array}{c}\text { No } \\
\text { Especialidad }\end{array}$ & $\begin{array}{c}\text { Infractores } \\
\text { norma } \\
\text { extracción }\end{array}$ & $\begin{array}{c}\text { Infractores } \\
\text { norma } \\
\text { cooperación }\end{array}$ & $\begin{array}{c}\text { Infractores } \\
\text { ambas } \\
\text { normas }\end{array}$ & Total \\
\hline $\begin{array}{l}\text { Ninguno } \\
\text { Menos de \$ 100.000 }\end{array}$ & 34 & 0 & 0 & 1 & 4 \\
$\begin{array}{l}\text { De \$ 100.000,01 a } \\
\quad \text { \$ 150.000 }\end{array}$ & 17 & 4 & 27 & 11 & 86 \\
$\begin{array}{l}\text { De \$ 150.000,01 a } \\
\text { \$ 200.000 }\end{array}$ & 11 & 1 & 10 & 6 & 34 \\
Más de \$200.000 & 10 & 1 & 5 & 2 & 19 \\
\hline Total & 82 & 7 & 3 & 2 & 16 \\
\hline
\end{tabular}

Fuente: Elaboración propia en base a resultado de encuesta.

En síntesis, los pescadores artesanales, miembros de las AMERB estudiadas que autodeclaran transgredir normas de extracción y cooperación al interior de sus organizaciones son relativamente jóvenes, con bajos niveles de educación, que poseen especialidad de buzos y que reportan bajos niveles de ingreso promedio mensual ${ }^{29}$.

${ }^{29}$ Reconocemos que esta caracterización, al estar basada en la agregación de infractores que pertenecen a las distintas organizaciones consideradas, puede no representar apropiadamente el perfil de pescadores infractores de una organización específica. El propósito de la caracterización es conocer los perfiles de los pescadores encuestados de acuerdo a su comportamiento respecto de cumplimiento de normas más que enfatizar en las diferencias por organización. 
4.3 Cumplimiento de normas según percepción de sanciones, legitimidad, sentido de pertenencia a las organizaciones, y percepción de los derechos

Con el propósito de identificar de manera más completa el perfil de los pescadores infractores de normas, a continuación extendemos el análisis considerando variables adicionales relativas a la percepción individual respecto de las sanciones, la legitimidad de las organizaciones y sus dirigentes, el sentido de pertenencia a la organización y la percepción de los pescadores respecto de los derechos de uso y explotación ${ }^{30}$.

Los resultados obtenidos en la encuesta sugieren que la totalidad de los infractores de la norma de extracción declaran conocer las sanciones por incumplimiento de normas establecidas por la organización. El mismo grupo considera además que las sanciones son justas. Menores porcentajes se observan para los no cooperadores y los infractores de ambas normas. En este último grupo tenemos que el 39\% de los encuestados considera que las sanciones actuales son injustas (véase Tabla $N^{0} 10$ ). Contrario a lo esperado, nuestros resultados sugieren la ausencia de efectos disuasivos netos sobre transgresiones de normas a partir del conocimiento y percepción respecto de las sanciones. No obstante, no es posible descartar que la imposición efectiva de las sanciones disponibles en las organizaciones sea percibida como improbable, reduciendo con ello el poder de disuasión de las mismas.

Otro de los factores que puede potencialmente determinar la adhesión individual a normas de las organizaciones, es el compromiso a través del sentido de pertenencia a la organización (véase por ejemplo Sutinen y Kuperan [1999]). Considerando la información de que disponemos, hemos decidido utilizar el número de años que el pescador está adscrito a la organización y la participación en actividades comunitarias, como variables que indican el grado de compromiso o sentido de pertenencia del pescador individual con la AMERB y sus normas. El número de años de pertenencia observada entre los pescadores encuestados fluctúa entre un mínimo de 1 año y un máximo de 15 años, con un promedio de 8,9 años. El máximo

${ }^{30}$ Más allá de la actividad de vigilancia e imposición de sanciones, la literatura ha enfatizado también el rol de variables sociales como determinantes de la decisión de cumplimiento en el caso de recursos de propiedad común. Entre ellas, la percepción respecto a la legitimidad de las regulaciones y sanciones, el sentido de pertenencia a una comunidad, niveles de participación, grado de desarrollo moral del individuo y presión social [véase, por ejemplo, Bardhan (1993), Sutinen y Kuperan (1999), Beckenkamp y Wiebke (2000), Cárdenas et al. (2000), Hatcher et al. (2000)]. El rol de la vigilancia y las sanciones para inducir cumplimiento en el caso de regulaciones pesqueras fue examinado en un trabajo pionero de Sutinen y Andersen (1985). 
número de años de pertenencia se presenta en el caso de pescadores de las organizaciones de Dichato y Lirquén, las que poseen mayor antigüedad. Los integrantes de las organizaciones en los segmentos de no infractores, infractores de la norma de extracción e infractores de la norma de cooperación presentan una media de número de años de pertenencia superior al promedio general. En contraste, los infractores de ambas normas tienen un período de permanencia en las organizaciones de 5,6 años, claramente inferior a la media general. Los resultados sugieren que los pescadores que tienen mayor tiempo de pertenencia a la organización presentan menor frecuencia de transgresión de las normas, es decir, la antigüedad en la organización parece ser un factor potencialmente determinante del apego y respeto individual a las normas de funcionamiento de las AMERB.

La encuesta consideró también preguntas relacionadas con la participación del pescador en actividades comunitarias. Se incluyen aquí la participación del individuo en actividades desarrolladas por la comunidad a la cual pertenece, y en la que se inserta la organización que gestiona la AMERB; entre otras, participación en actividades religiosas, equipos deportivos y juntas de vecinos. En lo que se refiere a la participación comunitaria, así definida, el 34\% de los infractores de la norma de cooperación declara no participar nunca de las labores desarrolladas en su comunidad; este porcentaje aumenta entre los infractores de ambas normas y los que aceptan haber transgredido la norma de extracción (62\% y 43 \%, respectivamente).

La encuesta también incluyó preguntas respecto a la percepción individual de los pescadores sobre la legitimidad de la autoridad, participación en la organización y percepción sobre sus derechos de uso y explotación como factores determinantes de la decisión de cumplimiento (Sutinen y Kuperan [1999], y Hatcher et al. [2000]). Respecto a la percepción de legitimidad de la autoridad, los resultados de la encuesta indican que solamente el 29\% de los infractores de ambas normas califican la labor de sus dirigentes como buena. Similar calificación le otorga el 71\% de los infractores de la norma de extracción y el 62\% de los no cooperadores. Estos resultados son esperados al considerar que el comportamiento en términos de cumplimiento puede estar determinado con la efectividad de la autoridad, es decir, los individuos que consideran que ésta no es capaz de solucionar sus problemas o tomar las mejores decisiones presentan una mayor probabilidad de tener un comportamiento en contra de las normas establecidas por la autoridad (véanse resultados en Tabla $\mathrm{N}^{\mathrm{o}} 10$ ).

En relación con comunicación y el uso de procesos de votación, se espera que la presencia de éstos ayuden a lograr mayores niveles de cum- 
TABLA No 10 :

RESULTADOS DE CUMPLIMIENTO DE NORMAS SEGÚN PERCEPCIÓN DE SANCIONES, PARTICIPACIÓN Y LEGITIMIDAD

\begin{tabular}{|c|c|c|c|c|}
\hline Variable & $\begin{array}{l}\text { No } \\
\text { infractores }\end{array}$ & Extracción & $\begin{array}{l}\text { Infractores } \\
\text { Cooperación }\end{array}$ & Ambas \\
\hline \multicolumn{5}{|l|}{ Sanciones } \\
\hline Conoce las sanciones & 0,96 & 1,00 & 0,97 & 0,85 \\
\hline Las considera justas & 0,82 & 1,00 & 0,86 & 0,61 \\
\hline \multicolumn{5}{|l|}{$\begin{array}{l}\text { Sentido de pertenencia a la } \\
\text { organización }\end{array}$} \\
\hline \multicolumn{5}{|l|}{ Tiempo de pertenecer a la } \\
\hline Participación comunitariab & 0,74 & 0,57 & 0,66 & 0,38 \\
\hline \multicolumn{5}{|l|}{ Reside en la caleta donde } \\
\hline $\begin{array}{l}\text { se encuentra la organización } \\
\text { Percepción legitimidad }\end{array}$ & 0,65 & 0,710 & 0,84 & 0,71 \\
\hline $\begin{array}{l}\text { Calificación labor de dirigentes } \\
\text { Indicador de participación }\end{array}$ & 0,69 & 0,71 & 0,62 & 0,29 \\
\hline Se toma en cuenta su opinión & 0,97 & 1,00 & 0,97 & 0,90 \\
\hline Asiste a las reuniones & 0,96 & 1,00 & 0,88 & 0,66 \\
\hline $\begin{array}{l}\text { Ejerce derecho voto } \\
\text { Derechos }\end{array}$ & 0,98 & 1,00 & 0,93 & 0,71 \\
\hline Conoce la ley de las AMERB & 0,81 & 1,00 & 0,95 & 0,90 \\
\hline Se considera dueño del recurso ${ }^{d}$ & 0,97 & 1,00 & 0,95 & 0,90 \\
\hline
\end{tabular}

a El pescador considera que la autoridad (SERNAPESCA, Carabineros, Autoridad de Puerto) se hace presente en el área más del $60 \%$ de las veces que es solicitada;

b El pescador dice tener una participación comunitaria superior al 30\% de las actividades desarrolladas en su comunidad;

${ }^{c}$ Califica la labor de los actuales dirigentes como buena;

d El pescador considera que el pertenecer a la organización le otorga derechos sobre los recursos del área de manejo.

Fuente: Elaboración propia en base a información recopilada en encuesta aplicada año 2003.

plimiento con normas de funcionamiento de las organizaciones. En este sentido observamos que la totalidad de las organizaciones estudiadas utiliza la votación como la forma de elección de autoridades y normas para la administración de los recursos. Contrario a lo esperado, casi la totalidad de los infractores (todos los infractores de la norma de extracción, 97\% de los no cooperadores y el 90\% de los infractores de ambas normas) considera que su opinión es tomada en cuenta al momento de definir las normas del área de manejo. En lo que a la asistencia a las reuniones se refiere, el mayor porcentaje de inasistencia corresponde a los infractores de ambas normas (34\% de éstos dice asistir a menos del 30\% de las reuniones), en contraste con el $100 \%$ de los infractores de la norma de extracción que dicen asistir 
siempre o casi siempre (más del 30\%). Adicionalmente, la totalidad de los infractores de la norma de extracción dice hacer valer su derecho a voto en las decisiones de la organización, lo mismo sucede con el 93\% de los no cooperadores, un comportamiento distinto muestra un $29 \%$ de los infractores a ambas normas (véase Tabla $\mathrm{N}^{0} 10$ ). Este resultado sugiere que la decisión de transgresión no está determinada por problemas de participación en las organizaciones, y que éstas en general mantienen en la práctica procesos participativos para la toma de decisiones ${ }^{31}$.

Con relación a la percepción respecto de derechos de uso, y considerando que la definición de los mismos es uno de los principales aportes del concepto de las AMERB al manejo y explotación de recursos bentónicos, los resultados indican que el 78\% del total de los encuestados dice conocer los derechos planteados por la Ley de Áreas de Manejo. En el grupo de los infractores, el 36\% de aquellos que reportan infringir la norma de extracción afirma no conocer la definición de derechos bajo el esquema de regulación de las AMERB. En tanto que el 40\% de los infractores de la norma de cooperación y aquellos que reportan infringir ambas normas dicen desconocer la referida definición de derechos. La proporción de pescadores artesanales encuestados que declara conocer los derechos de uso y explotación establecidos en la legislación de áreas de manejo puede ser percibida como excesivamente alta. Precisamos al respecto que la única pregunta específica realizada se planteó de la siguiente forma: “¿Conoce usted la definición de derechos de propiedad que plantea la Ley de Áreas de Manejo para los recursos bentónicos que se encuentran dentro del área?”. Consecuentemente, respuestas afirmativas no necesariamente implican un conocimiento detallado de los diversos aspectos legales que son relevantes en la definición de derechos, sino más bien, debieran ser entendidas como el conocimiento de los pescadores respecto de la posibilidad de manejar y explotar los recursos bentónicos del área que constituyen especies objetivos ${ }^{32}$.

${ }^{31}$ Dos precisiones respecto de este análisis. Primero, reconocemos que la frecuencia de las reuniones puede diferir no sólo entre organizaciones sino incluso período a período. Lamentablemente, no disponemos de información sobre este punto. Segundo, en relación con la participación a través del ejercicio del derecho a voto, además de votar respecto de materias rutinarias, los pescadores también ejercen su derecho a voto, entre otros, con el propósito de aprobar o rechazar cambios en el reglamento interno de las organizaciones y pronunciarse respecto de la aceptación o rechazo de solicitudes de ingreso de nuevos socios. Estas precisiones han sido motivadas por sugerencia de un árbitro anónimo de Estudios Públicos.

${ }^{32}$ Con el propósito de ilustrar este punto considérese por ejemplo que durante el trabajo de campo los pescadores mencionaron que, diferente de lo que ocurría en el pasado, en la actualidad no capturan el recurso que no cumple con los requisitos de talla y peso: "Antes al ver un loco sin importar su tamaño yo lo extraía, porque, si no lo hacía yo, el buzo que venía tras de mí se lo llevaría”. 
Finalmente, considerando las respuestas obtenidas a la pregunta respecto de si el pescador se considera dueño de los recursos del área de manejo asignada a su organización, se obtuvo que el 10,5\% de los infractores de las dos normas no considera que el ser miembro de la organización le otorgue derechos sobre los recursos del área de manejo. Entre los pescadores que no han infringido ninguna de las dos normas el 97,5\% considera que el ser miembro de la organización le otorga derechos sobre los recursos del área (véase Tabla $\mathrm{N}^{\circ} 10$ ).

En resumen, podemos decir, por una parte, que los pescadores que consideran legítima la autoridad de su organización y que tienen mayor tiempo de pertenencia a ésta presentan mayor cumplimiento de las normas establecidas. Por otra parte, los pescadores que dicen conocer los planteamientos de derechos considerados en la legislación sobre áreas de manejo y que consideran que dicha medida de administración define que ellos tienen derecho sobre los recursos del área por ser miembros de la organización, presentan también un comportamiento de apego a las normas estudiadas.

\section{Síntesis y conclusiones}

La creación y asignación de derechos de uso territorial a organizaciones de pescadores artesanales en la forma de áreas de manejo y explotación de recursos bentónicos constituye una innovación relevante de la política pesquera en Chile. En este artículo se han reportado resultados de un estudio de casos respecto de funcionamiento de las organizaciones de pescadores y del comportamiento de sus integrantes con relación al cumplimiento de normas definidas por las organizaciones.

Considerando los objetivos de la investigación, tendientes a describir la organización y normas de funcionamiento de las áreas de manejo, podemos observar que las organizaciones estudiadas presentan aspectos de organización muy similares en ámbitos tales como los mecanismos de votación y períodos de funciones de junta directiva, entre otros. Sin embargo, diferencias significativas en aspectos claves de funcionamiento caracterizan también a las organizaciones. Aspectos en que existen diferencias entre las organizaciones estudiadas son los sistemas de vigilancia para inducir cumplimiento, la comercialización de cosechas y la norma de distribución de beneficios.

En el caso específico de las actividades de vigilancia para inducir cumplimiento, se observan diferencias tanto en la frecuencia como en la extensión de los turnos. Adicionalmente, mientras en tres de las cuatro 
organizaciones el tiempo destinado a vigilancia no es remunerado, en una de ellas la vigilancia nocturna sí lo es. Otros costos originados en el desarrollo de labores de vigilancia, tales como materiales y equipos, son en algunos casos asumidos por la propia organización, la cual provee éstos, mientras que en otras organizaciones los costos son asumidos por los propios pescadores que deben cumplir con el turno de vigilancia.

En relación con la comercialización de la cosecha observamos que, en general, el proceso de negociación es realizado por un grupo de pescadores integrantes de las organizaciones. No obstante, en un caso la comercialización es individual. Esto sugiere que probablemente pescadores evitan negociar individualmente como una forma de mejorar su poder de negociación. Es interesante notar la existencia de contratos de distribución con anterioridad a la ejecución de la cosecha, fenómeno observado en una de las organizaciones. En ésta el comprador actúa como financista de capital de trabajo para la operación de extracción. Aunque no puede ser extrapolado a todas las organizaciones, la disponibilidad de mayores opciones de financiamiento de capital de trabajo podrían mejorar la posición negociadora de dicha organización. La diversidad de normas de distribución de beneficios de la cosecha es un resultado de interés. De acuerdo al análisis presentado en la sección 3, las organizaciones han desarrollado diversas formas de distribución de beneficios, las cuales en algunos casos son complejas, considerando tanto aspectos de género como también aquellos referidos al uso de equipos y especialidad de los socios en las faenas de cosecha.

En cuanto a resultados de cumplimiento, concluimos que existe mayor incidencia de transgresiones de norma de cooperación; sin embargo, la incidencia de transgresiones a prohibición de extracción del recurso loco es también significativa, de acuerdo a la declaración de los pescadores. Este resultado sugiere que las incidencias de violaciones trascienden la actividad ilegal desarrollada por miembros externos a la organización, la cual si bien no ha sido considerada en este estudio, es la que frecuentemente se indica como problema significativo para el adecuado funcionamiento de este sistema de administración. Adicionalmente, este resultado sugiere también implicancias respecto a la necesidad de mejorar los diseños de vigilancia al interior de las organizaciones. Ello es aun más relevante considerando que un alto porcentaje de pescadores infractores dicen tener conocimiento de que algunos de sus compañeros extraen recursos de manera ilegal. De este grupo un bajo porcentaje declara tener la convicción de que sus compañeros han sido castigados, sugiriendo de paso que la lealtad es un factor 
relevante para los pescadores que reportan transgredir la norma de extracción ${ }^{33}$.

Los resultados indican que los esfuerzos de la autoridad pesquera deben encaminarse a fortalecer junto a las organizaciones los sistemas de vigilancia y monitoreo. Esta conclusión se refuerza al considerar que la totalidad de los pescadores encuestados aceptan que el sistema actual de vigilancia debe ser mejorado, pero también exponen que de no ser por el sistema actual la extracción ilegal sería mucho mayor y pondría en riesgo la estabilidad del área. Es pertinente notar también que un problema importante que enfrentan las organizaciones es la extracción ilegal de parte de las personas que no son miembros de su organización y a quienes no tienen manera de sancionar. Al respecto, no obstante existen los mecanismos legales y los pescadores los mencionan, éstos son, a juicio de los pescadores, inefectivos; ya sea porque los medios de prueba para castigar a los extractores ilegales son difíciles de conseguir o por los problemas que enfrenta la autoridad para mostrar presencia en el área de manejo y/o realizar controles y eventuales detenciones ante la presencia de infractores o desarrollo de actividad ilegal. Lo anterior es una preocupación generalizada en las cuatro organizaciones, aunque se hace más evidente en aquellas que están geográficamente más alejadas de las autoridades formales (Candelaria Cantera y Puerto Yana). Este punto se hizo notar en las entrevistas realizadas, a pesar de la evidencia de esfuerzos desplegados por mejorar la comunicación entre el área y las autoridades formales, como lo es, por ejemplo, la habilitación de un equipo de radio comunicación en el caso de Yana — la organización más alejada de centros urbanos, entre aquellas aquí consideradas - y que fue dispuesto por la autoridad de puerto.

Considerando el alto porcentaje de los pescadores no infractores que declaran que ser miembros de la organización les otorga derechos sobre los recursos bentónicos que se encuentran dentro del área de manejo, es posible concluir que la definición de los derechos es un factor determinante de la decisión de cumplimiento de las normas estudiadas. Específicamente, el conocer la definición de derechos de uso y explotación y el considerarse

${ }^{33}$ El diseño específico de mejoramiento en los mecanismos para inducir cumplimiento de normas en las organizaciones excede los propósitos de este trabajo. Sin embargo, en principio, estos esfuerzos debieran concentrarse en aspectos referidos a nivel y distribución del esfuerzo de fiscalización, y el diseño y aplicación de las sanciones al interior de la organización. Adicionalmente, parece también apropiado considerar aquellos aspectos que puedan incrementar la percepción de legitimidad de las normas, la participación y el sentido de pertenencia de los pescadores a su organización. 
dueño de los recursos bentónicos al interior del área disminuye el incentivo a infringir. Este resultado es importante para la autoridad ya que indica que el concepto de áreas de manejo resulta ser beneficioso para inducir mejores niveles de cumplimiento y lograr un uso adecuado de recursos bajo este sistema de administración descentralizado.

Finalmente, y aunque no sistematizado en esta investigación, durante las visitas a terreno en el desarrollo del trabajo de campo, se pudo observar que al interior de las comunidades en que existen áreas de manejo, en particular en aquellas en las que se insertan las AMERB incluidas en este estudio, se presentan como fenómenos en desarrollo, división y problemas de relaciones entre los socios integrantes de las organizaciones signatarias de los derechos de uso y explotación y las personas que no pertenecen a la organización o socios que han sido expulsados. La situación tendría origen en que agentes no incorporados en las organizaciones discrepan de la exclusión al acceso a recursos que han sido considerados por siempre de libre acceso. Esto representa sin duda un reto para la autoridad porque indica la necesidad de buscar mecanismos efectivos de integración en las comunidades signatarias de las áreas de manejo. 


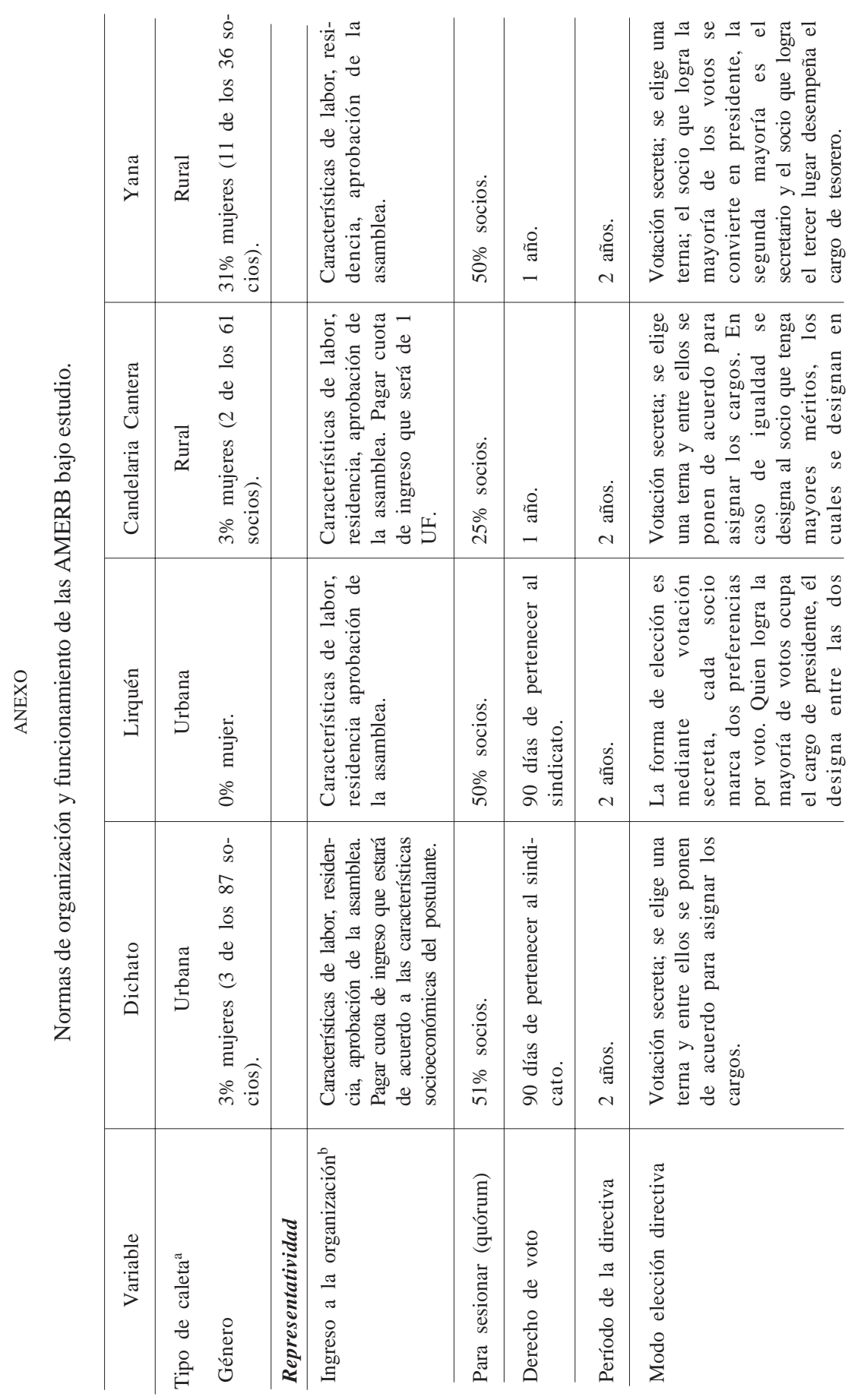




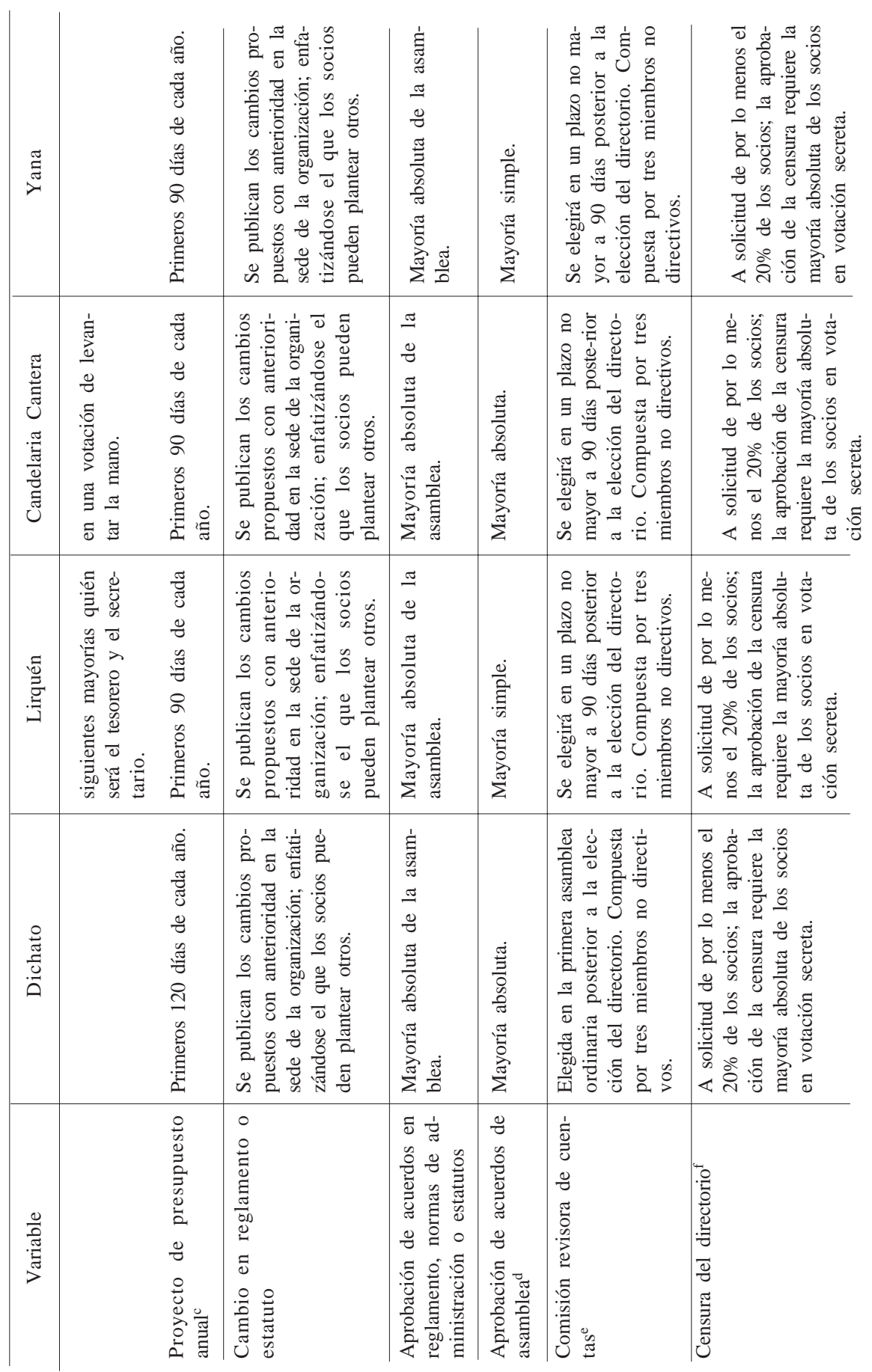




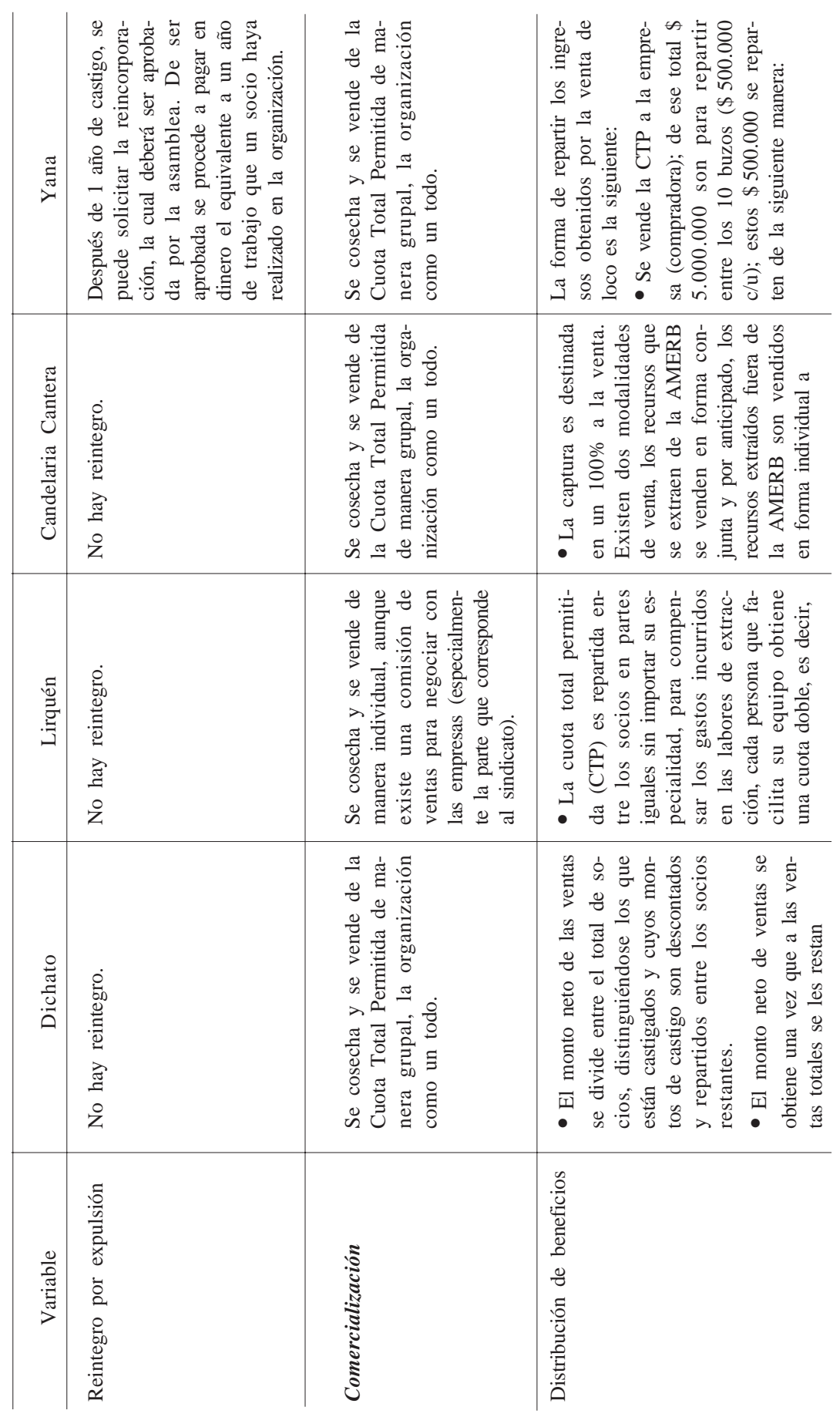




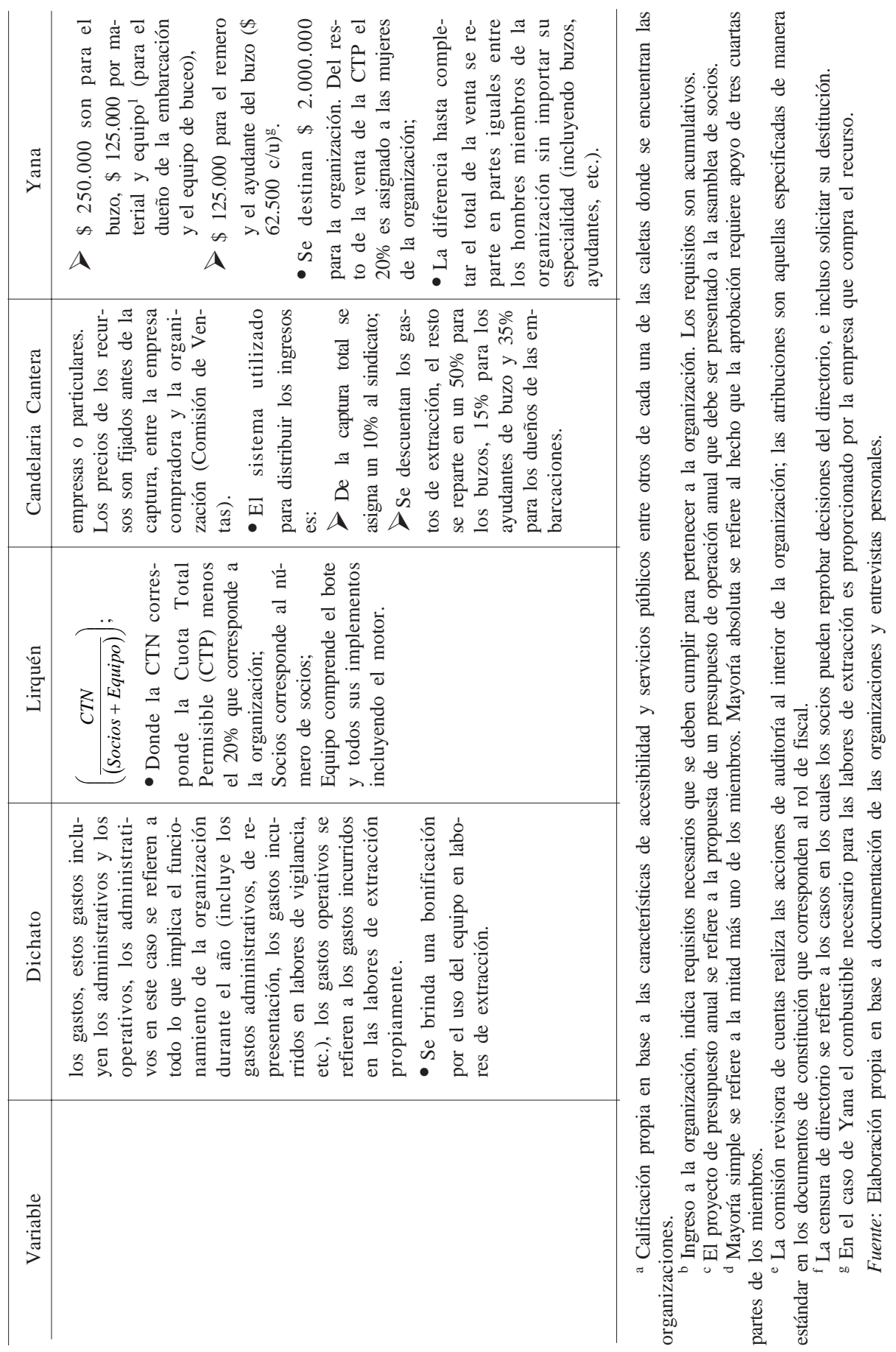




\section{REFERENCIAS}

Agüero, Max. 2001: "Seguimiento y Evaluación Social y Económica de las Áreas de Manejo y Explotación de los Recursos Bentónicos”. En Informe Final de Proyecto sobre Áreas de Manejo y Explotación de Recursos Bentónicos. Sercotec-Subpesca.

Beckenkamp, Martin y Gümbel Wiebke. 2000: “Emotional Appraisal of Different Situations in Common Dilemmas Depending on Social Orientation”. Documento no publicado, University of Saarsland / Psychology, IASCP 2000 Conference.

Berkes, F.; D., Feeny, B. J., McCay y J. M. Acheson. 1989: "The Benefits of the Commons”. En Nature 340 (13); July, pp. 91-93.

Cárdenas, Juan Camilo, John Stranlund y Cleve Willis. 2000: "Local Environmental Control and Institutional Crowing-Out”. En World Development, Vol. 28 (10), pp. 1719-1733.

Castilla, Juan Carlos y M. Fernández. 1998: “Small-Scale Benthic Fisheries in Chile: On Co-management and Sustainable Use of Benthic Invertebrates. En Ecological Application, 8 (Supplement), pp. S124-S132.

Cereceda, Luz y Darinka Czischke. 2001: “Áreas de Manejo y Explotación de Recursos Marinos Bentónicos. Nueva Modalidad Institucional para el Desarrollo Sustentable del Sector Pesquero Artesanal”. En Ambiente y Desarrollo, junio, pp. 4049.

González, Ezequiel. 1996: “Territorial Use Rights in Chilean Fisheries”. En Marine Resource Economics, Vol. 11, pp. 211-218.

Hatcher, Aarón, Shabbar Jaffry, Olivier Thébaud y Elizabeth Bennett. 2000: “Normative and Social Influences Affecting Compliance with Fisheries Regulations”. En Land Economics, Vol. 76 (3), pp. 448-461.

Jerez, Gabriel. 2001: “El Concepto de Área de Manejo como Base para la Conservación de los Recursos Bentónicos y su Aporte a la Biodiversidad Marina Costera Chilena”. En Sustentabilidad de la Biodiversidad. Universidad de Concepción, pp. 855-867.

Ministerio de Economía, Fomento y Reconstrucción, Gobierno de Chile. 1999: Ley General de Pesca y Acuicultura, noviembre, Chile.

Ministerio de Economía, Fomento y Reconstrucción, Gobierno de Chile. 2000: Reglamento sobre Áreas de Manejo y Explotación de Recursos Bentónicos, octubre.

Ostrom, Elinor. 1990: Governing the Commons: The Evolution of Institutions for Collective Action; New York: Cambridge University Press.

Seabrigth, Paul. 1993: "Managing Local Commons: Theoretical Issues in Incentive Design”. En Journal of Economic Perspectives; Volume 7; No 4 (Fall), pp. 113134.

Sindicato de Trabajadores Independientes, Pescadores Artesanales, Buzos Mariscadores Caleta Cantera (2003): "Reglamento Interno”. Talcahuano, Chile, febrero, 2003.

Subsecretaría de Pesca (SUBPESCA). 2001: “Consideraciones Técnicas ESBA, PMEA e Informe Anual”, Documento Técnico No 3, mayo. 
Subsecretaría de Pesca (SUBPESCA). 2000: “Áreas de Manejo y Explotación de Recursos Bentónicos”. Documento de Difusión No 1; junio.

Subsecretaría de Pesca (SUBPESCA). 1999. "Consideraciones Técnicas para la Elaboración del Estudio de Situación Base y el Plan de Manejo y Explotación del Área”, Documento Técnico AMERB No 2, Chile.

Sutinen, Jon, y K. Kuperan. 1999: “A Socioeconomic Theory of Regulatory Compliance in Fisheries”. International Journal of Social Economics, 26 (1/2/3), pp. 174-193.

Sutinen, Jon, y Peder Andersen. 1985: "The Economics of Fisheries Law Enforcement”. En Land Economics, Vol. 61(4), pp. 387-397.

Universidad de Concepción. 2001: "Primer Informe de Seguimiento para el Área de Manejo de Candelaria y Cantera, VII Región”. Concepción, Chile.

Villena, Mauricio, y Carlos Chávez. 2005: “On the Enforcement of Territorial Use Rights Regulations in Fisheries (TURF’s): A Game Theoretic Approach”. Por aparecer en Economía, Associaçao Nacional dos Centros de Pos-Graduaçao em Economia (Anpec), Brasil.

Walker, James, Roy Gardner, Andrew Herr y Elinor Ostron. 2000: “Collective Choice in the Commons: Experimental Results on Proponed Allocation Rules and Votes”. En The Economic Journal, pp. 212-234. 